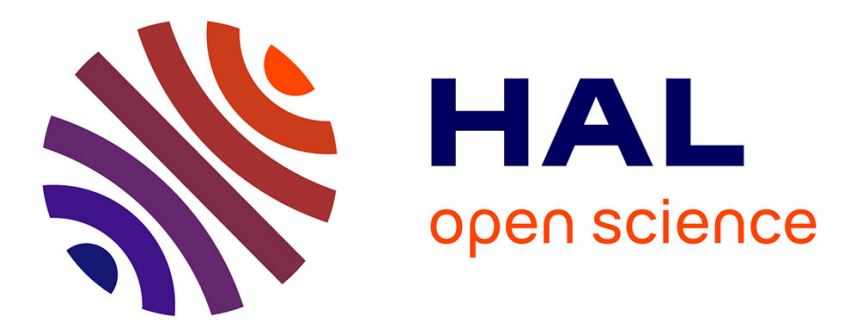

\title{
Term structure of psychological interest rates: A behavioral test
}

\author{
Hubert de La Bruslerie
}

\section{To cite this version:}

Hubert de La Bruslerie. Term structure of psychological interest rates: A behavioral test. Southern Finance Association 2010 Conference, Nov 2010, Ashville, USA, États-Unis. halshs-00536910

\section{HAL Id: halshs-00536910 \\ https://shs.hal.science/halshs-00536910}

Submitted on 17 Nov 2010

HAL is a multi-disciplinary open access archive for the deposit and dissemination of scientific research documents, whether they are published or not. The documents may come from teaching and research institutions in France or abroad, or from public or private research centers.
L'archive ouverte pluridisciplinaire HAL, est destinée au dépôt et à la diffusion de documents scientifiques de niveau recherche, publiés ou non, émanant des établissements d'enseignement et de recherche français ou étrangers, des laboratoires publics ou privés. 


\title{
Term structure of psychological interest rates: A behavioral test
}

\author{
Hubert de La Bruslerie \\ Professor of Finance*
}

\begin{abstract}
A lot of empirical and behavioral studies underline the idea of a non-flat term structure of subjective interest rates with a decreasing slope. Using an empirical test, this paper aims at identifying in individual behaviors whether agents see their psychological value of time decreasing or not. We show that the subjective interest rate follows a negatively sloped term structure. It can be parameterized using two variables, one specifying the instantaneous time preference, the other characterizing the slope of the term structure. A trade-off law called "balancing pressure law" is identified between these two parameters. We show that the term structure of psychological rates depends strongly on gender, but appears not to be linked with life expectancy. We also question the cross relationship between risk aversion and time preference. From a theoretical point of view, these two variables stand as two different and independent dimensions of choice. However, empirically, both time preference attitude and slope seem directly influenced by risk attitude.
\end{abstract}

Keywords: hyperbolic discounting, time preference, behavioral economics, psychological time value, risk aversion

$10 / 09 / 10$

JEL classification: C9, D03, D91

\footnotetext{
*University Paris Dauphine, DRM-Finance, Place du Mal de Lattre 75116 Paris France, mail: hlb@ dauphine.fr. I want to thank Florent Pratlong, University Paris I Sorbonne, for his help in designing the questionnaire. This paper benefited from comments of Franck Moreau, University of Rennes I, Yi-Kai Su, University of Taiwan. It was presented at the HEC Geneva seminar of Finance, at the $7^{\text {th }}$ AFFI International Finance Meeting in Paris, at the 2010 EFMA Annual Conference in Aarhus.
} 


\section{Introduction}

If risk aversion is an important feature of economic and financial behaviors, the attitude of an agent with regard to time is also fundamental. The subjective value given to time, also known as the subjective interest rate or the subjective value of time, is identified as a core concept of the microeconomic literature. It is a fundamental parameter, which enters into economic or financial choices. We know that choices are comparisons between pleasures and pains (Bentham, Introduction to the Principles of Morals and Legislation, 1789), which are estimated at different times, now and in the future. The weighting factor of choices that makes preferences is subjective utility. The time dimension is rooted in the economic process of choice because different periods are considered. It is for this reason that we need to consider not only a subjective interest rate to discount future utility, but several subjective interest rates allowing the definition of a subjective or psychological discount function. There is a difference between the subjective interest rate, which is a variable used by an agent to discount his future utility, and the time preference hypothesis. The time preference hypothesis refers to the idea that an agent has a "preference for immediate utility compared with a future utility" (Frederick et al., 2002, p. 351). We assume here that the economically rational agent has a positive subjective interest rate. He discounts future utility. As a consequence, the time preference hypothesis implies that the rational agent (i) needs to subjectively evaluate time, (ii) discounts future utility and (iii) develops a set of multitemporal choices. Moreover, the subjective interest rate is often submitted to an additional hypothesis: it is assumed to be constant whatever the age of the individual or the time horizon considered in the choice. This is the standard micro-economic setting of individual choices. Combined with the hypothesis of time invariance of preferences (involving time separable utility function), it leads to the classical model of maximization of the sum of discounted future utilities, as introduced by Samuelson (1937). Individual decisions using a unique and constant subjective interest rate will refer to an exponential discounting function. In equilibrium models of consumptioninvestment, choices are specified with regard to a representative agent, which allows the consideration of available aggregated variables.

\footnotetext{
${ }^{1}$ The hypothesis of "pervasive devaluation of the future" was presented by Ainslie and Haslam (1992, p. 59).
} 
The hypothesis of a unique and constant subjective interest rate is very useful for further modeling and empirical tests. Using market equilibrium variables or the aggregate values of investment of a representative agent is easy. However, it involves a very poor view of intertemporal choice setting by individuals. Many empirical and behavioral studies underline the idea of a non-flat term structure of subjective interest rates with a decreasing slope. This hypothesis has to be crossed with individual behaviors.

This paper aims at identifying whether agents see their psychological value of time as decreasing or not. We questioned a sample of 243 individuals in order to analyze their attitude with regard to time. They were asked to give to time different psychological values at different points in the future. The difficulty here is staying at the psychological value level and not questioning a monetary value of time. Public interest rates are social prices of time in a market and they appear as alternative saving or investment goods. Here, we want to question not the utility of saving goods or financial assets, but the intertemporal comparison of personal utilities (wherever they come from). The psychological value of time derives from the individual perception of choices between the current "self" of the individual at time $t$ and his future "selves" at times $\mathrm{t}+1, \mathrm{t}+2 \ldots$ We show that the subjective interest rates are specific to each individual. They have a decreasing form coherent with a negatively sloped term structure. They can be parameterized using two individual parameters, one specifying the immediate term preference, the other characterizing the slope. A trade-off law is documented between the two parameters, which appear to follow a log-log relationship common to any individuals. The term structure of psychological interest rates does not appear linked with life expectancy, but strongly depends on gender. Individual subjective time preference does not show a tempus fugit effect.

Individual preferences are conditioned by few variables. A cross relationship between risk aversion and time preference is often questioned, at least on theoretical grounds. These two concepts stand as two different and independent dimensions. Empirically, time preference attitude and slope seem directly influenced by attitude with regard to risk.

The following paper is divided into 5 Sections. The first presents a review of the literature. Section 2 introduces the concept of free time and the questionnaire. Section 3 gives the results and tests some assumptions. Section 4 estimates the term structure of subjective 
interest rates. The determinant variables explaining the subjective interest rates are analyzed in Section 5.

\section{1-The literature}

Fisher (1930) introduced the concept of rate of impatience in microeconomics choices. Samuelson (1937) developed a normative model of intertemporal choice using the discounted value of expected future utility. The idea is that an individual maximizes a set of utilities at different current and future periods. Referring to a "time separation" hypothesis, each periodic and specific future utility can be discounted. Individual choice will result from the combination of the utility dimension (which is itself influenced by the attitude toward risk) and the time dimension. The individual psychological price of time, also referred to as the rate of impatience, is an economic variable per se needed to build economic choices. Discounting the consequences of future decisions is at the heart of individual behaviors according to the standard micro-economic theory. The agent considers globally current and future expected utility, the latter being forecasted using available information. Samuelson introduces an identical subjective rate of interest, which results in a simple exponential discounting function in the standard microeconomic model.

$$
\operatorname{Max} E_{0}\left[\sum_{t=0}^{\infty} \delta^{t} U\left(C_{t}\right)\right]
$$

$\delta$ : annual constant psychological discount factor

$C_{t}$ : consumption at period $\mathrm{t}$

$U\left(C_{t}\right)$ : consumption utility

Time is an economically valuable dimension. Von Mises (1949) recognizes the time preference hypothesis. ${ }^{2}$ He consequently mentions that individuals give a psychological value to time and their impatience rate should not be assimilated with the interest rates in the financial markets. Interest rates are the social price of time and are used to compare alternative consumption and investment opportunities. The psychological interest rate is used to discount subjective evaluation by individuals in their calculus, what he calls "economization". For Von Mises, "The economization of time is independent of the

\footnotetext{
${ }^{2}$ Op. cit. chap 18, p. 481; "Time preference is a categorical requisite of human action".
} 
economization of economic goods and services. Even in the land of Cockaigne man would be forced to economize time, provided he were not immortal and not endowed with eternal youth and indestructible health and vigor. Although all his appetites could be satisfied immediately without any expenditure of labor, he would have to arrange his time schedule, as there are states of satisfaction which are incompatible and cannot be consummated at the same time. For this man, too, time would be scarce and subject to the aspect of sooner and later". ${ }^{3}$ The analysis of the variables which may explain individual time preference is very rich: remaining duration of life, health, youth will affect the level of the subjective interest rates. This approach opens the way to subjective interest rates, which are variable through time for the same individual according to his expected duration of life or his health. This is the first mention of a possible terms structure in the psychological value of time. A major theoretical question is set. Does intertemporal attitude depend on visceral features and is constant or, as suggested by Von Mises, does it depend on contingent variables?

Later and independently, this theoretical hypothesis was reinforced by empirical research questioning the exponential discount function. Empirical tests were developed to see whether individual subjective interest rates are constant whatever the time horizon of the choice. These tests generally invalidate the idea of flat impatience rates and lead to the conclusion of a decreasing term structure. Thaler (1981) was among the first to sustain that hypothesis by questioning individuals: "Which amount in respectively 1 month, 1 year or 10 years would you judge equivalent to 15 dollars now?” The median answers were $\$ 20$ in 1 month, $\$ 50$ in 1 year, and $\$ 100$ in 10 years' time. Thaler deduced a decreasing term structure of impatience rate with values of $345 \%$ for the one month horizon, $220 \%$ for the one year and $15 \%$ for the 10 years.

Experimental tests of the psychological discount function have been made on human individuals or animals by psychologists or psychiatrists. Chung and Herrnstein (1961) draw the conclusion that a decreasing hyperbola fits well the time preference function of animals. Considering human individuals, Ainslie (1992) and Loewenstein and Prelec (1992) model discount functions such as the hyperbolic curve $\delta(t)=(1+\alpha \cdot t)^{-\gamma / t}$, with $t$ being the time horizon. This curve gives decreasing equivalent annual interest rates. The immediate subjective interest rate is equal to the parameter $\gamma$. Long-term psychological rates converge toward zero.

\footnotetext{
${ }^{3}$ Op. cit., chap 5, p. 102.
} 
The decreasing term structure, as suggested by a hyperbolic model, would entail overdiscounting the immediate future vis-à-vis the far distant future. On the other hand, a flat term structure would ceteris paribus result in overdiscounting the distant future. The characteristics of hyperbolic (or any decreasing) subjective term structure is that the long-term future accounts for relatively more in solving the dynamic choice problems than the short term future. At the extreme, a myopic individual, who considers only the current period and the one that follows, will need only a short-term discount rate for the next period and is not concerned by the time inconsistency problem for onward periods (Loewenstein et Prelec, 1992). Laibson (1996) suggests the use of a "quasi-hyperbolic" discount function, which refers to two parameters: the standard discount coefficient $\delta$ and a second parameter $\beta<1$. At period $\mathrm{t}=1$, the discount coefficient is $\beta . \delta$. The following coefficients are multiplied by the unique $\beta$ coefficients. This results in a discrete discount function $\left\{1, \beta . \delta, \beta \delta^{2}, \beta . \delta^{3} \ldots\right\}$. He was one of the first to mention that economic agents are more impatient when they undertake short-term arbitrage than when they make economic choices within a long-term horizon.

The theoretical problem with a non-flat term structure of psychological interest rates is their time inconsistency. The sequences of economic choices are ex ante incoherent, which is not rational in the homo economicus setting. The optimal choices that are calculated for period t using a discount factor $\delta(\mathrm{t})$ are not the same as those that will be preferred one period later using a factor $\delta(\mathrm{t}-1)$ and discounted. Strotz (1956) underlined that ex ante the two sequences of consumption plans are dynamically incoherent. Time consistent setting of present and future consumptions using the available information implies that individuals cannot be irrational. Therefore the (only) simple solution is that psychological interest rates should be constant. However, in a situation of dynamic time inconsistent plans, intertemporal choices can also be analyzed as a conflict between different economically calculating agents, existing in the same individual. As Laibson (1996) points out, the "self" who decides at time $t$, enters into a strategic game with the optimizing "self" at time $t+1$. The multiple "selves" model is a way to cope with the "time inconsistency" consequence involved in non-flat psychological interest rates. Multiple "selves" is a psychological concept that allows the characterization of the peculiar nature of intertemporal choices (Frederick et al., 2002). On the other hand, time inconsistency may also derive from evolving preference functions such as “changing taste" preferences (Kahneman and Tversky, 1979; Tversky and Kahneman, 1992). 
Thaler and Shefrin (1981) introduced the concept of multiple selves in a nonformalized way, which did not lead to a testable hypothesis. They analyzed the consistency of temporal choices in a theory of "self-control". The agent has two "selves" in a conflict. The same individual is assumed to be at the same time a "planner" who organizes his consumption-investment choices looking at the long term and a myopic agent making choices on the very short-term horizon (a "doer"). The "doer" optimizes looking only at the next period. A conflict arises between the two different series of preferences. Thaler and Shefrin (1981) draw an analogy with agency conflict between manager and shareholders in a firm. The agent's "self control" is a way to reduce the conflict between the planner's self and the doer's self. The only way for the planner to modify the myopic doer's behavior is to control his behavior. This can be done either by modifying his preferences, or by imposing constraints or commitment rules to curb his choices. The devices to curb the behavior are classically incentives or rules. For instance, looking at the trade-off between consumption and investment, incentives may influence the behavior of the myopic agent by giving a strong moral and ethical value to saving. Self-limitation rules may be set to limit consumption and favor abstinence (equivalent to appetite suppressants for people who want to follow a diet regime).

Kahneman (1994) introduces a distinction between "decision utility", which results from choices consciously made by an individual, more precisely the consequences of his choices, and "experienced utility". Experienced utility stands at the global level of an individual's well being. The difference between the two refers to "basic" needs and the psychological concerns of human beings (Frederick et al., 2002). In a behavioral approach, there are indirect utility elements that are exogenously given, received or inherited from the context of the individual, or they may also be an indirect consequence of his choices. These elements will depend on the context of the individual, on previous choices, on pure random externalities and on tensions between the different "selves" that make a personality and a character. The individual context links past to future choices. In the economic dimension, the difference between "decision utility" and "experienced utility" is a difference in linkage with a decision made at time $\mathrm{t}$; it suggests that the instantaneous utility function is not constant.

In a behavioral approach, "time separability" exists and means that the individual can identify the instantaneous utilities from which he can build his global utility: global utility is 
"the temporal integral of some transformation of instant utility". ${ }^{4}$ Temporal aggregation means that the individual can compare two instantaneous utilities at different time periods by evaluating which one has the most important hedonic value. We are still in a psychological economic rationale of preferences. Kahnenam and Riis (2005, p. 8) add that "time is the last human resource of his life and find a way to use it at best is an important goal both for the individual involved in his well-being and at the level of social choices aiming at human wellbeing". This leads to the idea of time preference or positive psychological time value. This also entails questions on the upper limit with regard to aggregating future instantaneous utilities. The end of human life imposes a limit in the definition of his time personality. The successors of the agent (his children, global society...) are not his economic "selves". His identity will in the end die and be replaced by other actors and other preferences. This does not imply that the agent is indifferent to what can happen after his death. He can derive utility in passing on wealth or economic goods. His successors (if any and ex ante identified) will have different personalities and preferences.

The idea of identity involves consciousness of the structure of one's preference: Is the agent conscious of the stability/instability of his tastes? Am I the same now as I was yesterday? Will I be the same tomorrow? There is as much strength of differentiation and of continuity between the "selves" of the same individual within time as there are between different agents who are close to each other and living at the same time in the same social group. In analyzing economic behavior, discounting temporal preferences is as rational as socially aggregating individual preferences. According to Frederick (2006): "It may be just as rational to discount one's (self) future utility, as to discount the utility of another distinct individual, because the distinction between the stage of one's life may be as deep as the distinction between individuals". 5 The theoretical questions raised by intertemeporal discounting are numerous and are listed in Soman et al. (2005) or Rohde (2010) for an axiomatic point of view. Experimental studies have privileged individual choices and answers. In that sense, they convey more information than looking at aggregated market data. Feather and Shaw (1999) try to evaluate the leisure opportunity cost of beach sports. This cost is traditionally estimated to be a fraction of the wage rate. A problem arises for individuals who are not employed and have no observable wages. The demand for leisure will depend jointly on the pure time preference and on the wage rate. The time devoted to work is not a

\footnotetext{
${ }^{4}$ Cf. Kahneman et al. (1997), p. 388.

${ }^{5}$ Cf. art cit. p.674.
} 
discretionary continuous variable that an agent may easily optimize. Feather and Shaw underline that the "value of time" is not only given by a trade-off with the wage rate; it also depends on other hedonic variables. An estimate of the "shadow price of leisure time" is proposed by Lew and Larson (2005) in their evaluation of the discretionary wage. This concept assumes that the agent stands at his equilibrium between work and leisure and can make a trade-off. The evaluation of the leisure consumption is stochastic and is empirically estimated with regard to the consumption of leisure on Californian beaches. The implicit prices of leisure time are very different. They are high for employed or over-employed individuals, and lower for retired, unemployed and students. Warner and Pleeter (2001) analyzed the choices made by 60,000 American army members who were offered the choice of either a life annuity or an immediate indemnity on leaving the army. The actuarial rate used to define the annual cash flow was $17.5 \%$, at a time when the interest rate offered in the financial market was $7 \%$. The annual cash flow choice appeared financially better than the immediate payment. The empirical study showed that half of officers and around $10 \%$ of soldiers and civil employees chose the annual installments. This result evidences a very strong individual preference for the present time. The estimates of the psychological interest rate of army members by Warner and Pleeter were between $24 \%$ and $42 \%$.

Shapiro (2005) made an empirical study of American individuals who benefited from a free allocation of "food stamps". These subsidies are granted monthly. It was shown that the caloric consumption of those receiving the food stamps decreased by between 10 and $15 \%$ during the month. This implies a strong short-term preference. Calibrating a time preference function of a logarithmic agent, Shapiro obtains a daily subjective time discount coefficient of 0.996. Under the hypothesis of an exponential discount function, this is equivalent to an annual discount coefficient of 0.23 on a one-year horizon, i.e. a subjective interest rate of $320 \%$ per year. This estimate is viewed as too strong, so Shapiro questions the exponential subjective impatience hypothesis and uses the Laibson (1996) quasi-hyperbolic function to calibrate the data. With an estimated $\beta$ of 0.96 , he concludes that a hyperbolic function is better suited to high interest rates on the short-term end of the time preference curve. Kurz et al. (1973), using a simple questionnaire, concludes that the annual subjective interest rate is within the $36 \%$ to $76 \%$ range. Thaler and Shefrin (1981) also asked a very simple question: "Which money bonus do you want now instead of a 100 dollars bonus in a one year's time?". They highlight the influence of conditioning variables such as age, income level and marital status. They insist on the relationship between age and maturity: young people have to learn 
and internalize the technique of behavioral self-control. Social categories are also important in explaining the subjective interest rate. Thaler and Shefrin evoke a decreasing structure of subjective interest rates. In the long term, agents are relatively more patient: for instance, I prefer two apples within 101 days from now than one apple within 100 days. However, in a short-term view, the rate of impatience is different: I prefer one apple now than two apples tomorrow. Frederick et al. (2002) collected the estimates of subjective discount factors resulting from thirty experimental studies. They crossed these subjective values of time with the time horizon of choices ranging from the very short-term (10 dollars now versus $\mathrm{X}$ dollars tomorrow) to the very long-term (10 dollars now versus $\mathrm{Y}$ dollars in 10 years). The average discount factors (average subjective interest rate) showed an increasing (decreasing) structure with the time horizon term structure. Frederick et al. point out that questions based on money comparisons may be polluted with the idea of the interest rate, which is a social and marketable price of time and not a subjective time preference used by individuals to set their personal choices.

Many experiments and studies have tried to identify the conditioning variable explaining individual time preference attitudes. The influencing variables are:

- Attitude of smokers: smokers have a psychological price of time, which appear higher as compared with non smokers (Baker et al., 2003, Kirby and Petry, 2004, Ohmura et al., 2005).

- Alcohol dependency: alcoholics have a larger psychological price of time. Serious alcoholics discount future gains to a greater extent than do former alcoholics (Petry, 2001, Bjork et al., 2004). The same is true for drug addicts (Bretteville-Jensen, 1999, Kirby and Petry, 2004).

- Wealth level: rich households present subject interest rates that are 3 to $5 \%$ lower than households with low income (Lawrance, 1991).

- Age: Young people are moderately patient (i.e. they have a low psychological price of time). Patience increases with age and senior people have a larger psychological price of time (i.e. a lower discount factor) (Green et al., 1994). Life expectancy appears to influence and attenuate the relationship with age.

- Cognitive ability: Frederick (2005) shows the influence of cognitive abilities. In his test, he uses an index of "cognitive reflection" (CRT, "Cognitive Reflection Test"), which spans the difference of behavior between individuals who behave intuitively without taking the time for reflection and those who act taking the time to analyze and 
evaluate choices. The CRT index was crossed with both the dimensions of time preference and risk aversion using a sample of 3,428 respondents. A positive relationship between the CRT index and patience was highlighted: people showing high cognitive reflection are also more patient. A link was identified with risk attitude: people with a high CRT index are more prone to risk.

- Gender is a fundamental characteristic in the psychological valuation of time. For instance, Frederick (2005) shows that women have a lower CRT index (correlated with impatience and a higher time preference) than men.

- Risk aversion also seems to play a role. According to Frederick (2005), there is a common factor behind time preference and risk aversion. This hypothesis is important because it would mean that the two dimensions of risk aversion and time preference may be linked in human choices.

\section{2-The concept of free time and the questionnaire}

One important issue when dealing with individual time preference is knowing whether questions and choices have to be set in monetary units or not. Using a money equivalent places the individual in a framework of consumption power and leads to an underestimation of the answer. People are systematically exposed to confusion with saving decisions and interest rates. Comparing amounts of money now and later in the future is a saving choice and that decision is polluted by the existing possibility of deferring power consumption using existing market interest rates. When the outcomes are monetary, a normative behavior is based on Irving Fisher's assertion that rational decision makers will borrow or lend so that their marginal rate of substitution between present and future money will equal the market interest rate." As Read (2004) points out, "discount rates that exceed the opportunity cost of capital represent irrational behavior". The pure time preference is independent of the content of current and future choices between consumption and saving. We need to compare the utility of consuming a product now and the utility of consuming the same product in the future. Comparison of "moneyed choices" refers or suggests interest rates and introduces confusion between the psychological price of alternative utility choices and the social price of time. Cairns and Van der Poole $(2000,2002)$ first used questionnaires with questions comparing amounts of money. Later they privileged studies without any reference to money 
and compared dealing with a disease now with the possibility of deferring its onset further into the future.

The psychological value of time is the discounted factor applied to choice involving the future. This element is crucial in the dimension of intertemporal comparison at different times. The valuation ratio of two (utility) choices does not have a value in itself; it has a value relative to individual choices. It is not a general and shared price; it is a subjective ratio that should not be expressed in monetary units. Time is an open window for present and future choices and, possibly, future utility. Deferring or accelerating these choices expresses the personal value given to time. The idea of "free time" is used to identify an extra opportunity opened up to individuals to make new choices now or in the future. It does not say anything about the content of these choices. When comparing two apples in the future and one apple now, comparison develops within the framework of the utility of a given choice, i.e. to eat an apple. This involves the specific utility of an apple for someone who is fond of apples or that of another individual who hates apples. The idea of marginal free time opens up the space for new choices and additional utility independently of the content of the choice and the utility of the decision made within this new deferred opportunity to act economically. This free time is a window through which to enter into new economical and behavioral choices. It is not per se a set of substantial choices. It may have no value; it is not automatically linked to the consumption of goods, additional time to work or salary. The unit is "one hour of free time", not its value in euros. This "free hour" is given once in the time horizon and is compared with other amount of "free time" given once in the near or far future. To our knowledge this concept has not been used in the previous empirical literature. This approach is not exposed to the "changing taste" hypothesis which states that a comparison between utilities linked to the same good at different time can be explained by a possible evolution of the intrinsic utility of the good through time. This is the "Horse and the Rider" metaphor mentioned by Soman et al. (2005). Rational agents can forecast the evolution of their future utility function. However, a projection bias is identified by Loewenstein et al. (2003) who explain that the agents make their future tastes similar to their current tastes. The idea of "free time" disentangles time preference from the other factors that drive people to devalue future outcomes.

An additional hour of free time at period $t$ is compared with an additional hour of free time later. The hypothesis of time preference means that an hour of free time now is more 
valuable than one hour of free time later in the future. The relative ratio between the two gives an implicit price, which is the individual's subjective interest rate.

\section{The questionnaire}

The questions and a preliminary form were firstly tested on marketing students of the master's degree of the University Paris Sorbonne (Jolibert and Jourdan, 2006). These answers were not considered in the subsequent main test. The form itself is structured in four blocks of questions. The questionnaire was anonymously submitted to individuals. The first block of questions (block S) are questions about the characteristics of the respondent. Characteristics are unambiguous: date of birth, gender, place of birth, native language...(see Annex 1) Questions related to attitude and behavior cover the perception of time, the importance of passing on something to one's children; three questions are devoted to attitudes regarding risk and risk aversion (S21, S22, S23). Two questions propose a traditional choice between playing an uncertain lottery and a certain income. Personal attitude vis-à-vis the risk is questioned on a scale between risk-lovers and absolute risk averters.

The block A questions introduce the idea of "free time". What we want to analyze is the attitude vis-à-vis a pure space of time open to any economical or behavioral choice. When giving the form to respondents, we introduced the questionnaire by saying: "imagine that a day is now 25 hours instead of 24 , what is the importance of that extra new hour for you?". We want to identify individual preference for an extra space of choices before these choices are effectively made. In that sense, we do not need to rely on rational assumptions linked to choices. Respondents are faced with choices and the valuation of their utility. We want to compare the preferences of this extra window of space for new choices between, for instance, now and $\mathrm{X}$ years in the future. Respondents were asked to compare a period of free time now and a period of free time at a given time in the future. We recognize that this setting makes two implicit behavioral assumptions: (i) the additional value of one awarded "free hour" is symmetric to the value of one free hour subtracted from the daily time horizon ("imagine that a day is now 23 hours instead of $24 \ldots$..") (ii) the imagination of each one has to fill this new extra space of time. The way each one may fill this new pure time depends on the context of an economic choice led by scarcity of time (Von Mises, 1949). The way someone imagine leisure for instance is not the same if he is retired or if we focus to active people facing a 
leisure/work choice. Busy executives may systematically view "free time" as leisure. Here, fortunately our sample is composed of students and retired people and not of executives.

A1.-Would you prefer 1 extra hour of free time now or 2 hours of free time in 1 year's time?

A2. -Would you prefer 1 extra hour of free time now or 5 hours of free time in 5 years' time?

A3. -Would you prefer 1 extra hour of free time in 1 year's time or 5 hours of free time in 6 years' time?

A4. -Would you prefer 2 extra hours of free time in 10 years' time or a set of 1 hour of free time now and 1 hour of free time in 20 years' time?

A5. -Would you prefer 4 extra hours of free time in 10 years' time or a set of 1 hour of free time now and 1 hour of free time in 20 years' time?

A6. -Would you prefer 2 extra hours of free time in 5 years' time or a set of 1 hour of free time now and 1 hour of free time in 20 years' time?

A7. -Would you prefer a set of 1 extra hour of free time now and 1 hour of free time in 20 years' time or 2 hours of free time in 10 years' time?

A8 -Would you prefer to have in 10 years' time 2 hours of extra free time for yourself or to get in 10 years' time a set of one hour of free time for yourself and 1 hour of free time for one of your relatives?

Table 1 - Block A questions

(Answers with 3 alternative choices: first alternative, second alternative and indifference between the two choices. Indifferent choices would not be considered in the analysis)

Block B is a series of six questions on the relative value of one hour of free time in the future compared with one hour of free time now. Nine ordinal choices are proposed linked with a range of values expressed in number of hours. For instance, item 3 refers to a range of [2 to 6] hours. Respondents were asked to compare one hour of free time now and X hours in the future. By checking item 3, the respondent is showing that he considers one hour of free time now to be equivalent to 2 to 6 hours in the future. Different time horizons are questioned: 1 year ahead, 5 years, 10 years, 20 years, 30 years and 50 years corresponding respectively to questions B1 to B6. Questions B7 and B8 deal with curvature comparing a package of 15 hours of free time at two time horizons and 15 hours awarded at a medium term horizon. 
Questions B1-B6 are as follows: One extra hour of free time now is equivalent to how many hours of free time in 1 year's time (respectively 5 years, 10 years, 20 years, 30 years and 50 years)? The answer should be one of the 9 ordered choices:

1- Less than $1 \mathrm{~h}$ in 1 year (respectively $5,10,20,30,50$ years)

2- $\quad$ Between $1 \mathrm{~h}$ and $2 \mathrm{~h}$ in $1 \mathrm{y}(\mathrm{id})$

3- $\quad$ Between $2 \mathrm{~h}$ and $6 \mathrm{~h}$ in $1 \mathrm{y}(\mathrm{id})$

4- $\quad$ Between $6 \mathrm{~h}$ and $12 \mathrm{~h}$ in $1 \mathrm{y}(\mathrm{id})$

5- $\quad$ Between $12 \mathrm{~h}$ and $22 \mathrm{~h}$ in $1 \mathrm{y}(\mathrm{id})$

6- $\quad$ Between $22 \mathrm{~h}$ and $36 \mathrm{~h}$ in $1 \mathrm{y}(\mathrm{id})$

7- $\quad$ Between $36 \mathrm{~h}$ and $52 \mathrm{~h}$ in $1 \mathrm{y}(\mathrm{id})$

8- $\quad$ Between $52 \mathrm{~h}$ and $78 \mathrm{~h}$ in $1 \mathrm{y}$ (id)

9- $\quad$ More than $78 \mathrm{~h}$ in $1 \mathrm{y}(\mathrm{id})$

The same questions were submitted again after the respondent was asked to read a mortality table. In the block $\mathrm{C}$ questions, people had to compute their life expectancy taking into account their date of birth and their gender. Each respondent had to calculate the probable year of his death and his expected remaining duration of life from the present day. Then, after being informed of his true average life expectancy, questions identical to B1-B8 were asked again (questions C6-C13).

The block $\mathrm{C}$ questions will be used to cope with the problem of perception of time. The respondent may answer according not to the objective duration of time but his own perception of time. Zauberman et al. (2009) claim that seemingly impatient choices and hyperbolic individual discounting, may be explained by the subjective perception of time. A discrepancy appears in empirical test and the subjective sensitivity to an objective variation in time is low. The Weber-Fechner law states that the relationship between the objective time change and its subjective perception follows a logarithmic function. This one contracts the objective time stimulus (Zauberman et al., 2009).

\section{$\underline{\text { Data }}$}

The sample was put together from answers from 243 individuals. Two different categories of people were questioned using the questionnaire form. Most of the respondents were students from the Paris Sorbonne University. They are following management and 
business economics studies and are in the graduation year of their bachelor's or master's degree. A sub sample of retired people aged 58 or more were interviewed in the French city of Reims (26 people) and by sending the questionnaires by mail to retired men and women in rural areas of France (32 respondents). ${ }^{6}$ They were members of a non-profit organization for retired people. ${ }^{7}$ Their average age was 67.1 years. The student sub-sample (185 people) was on average 22.1 years old. The two sub-samples are very distinct since we did not have any respondents born in the 1958-1976 period.

The questionnaire was answered during the academic year 2007-2008. The global average age of the whole sample was 32.8 years. Of the total sample, 58\% were women. Only 56 respondents (23\%) had children (average number of children was 2.03); 47 were grandparents. 88 of the respondents $(36.5 \%)$ had thought about passing on something to their children. Of the others, 106 (44\%) said they would think about it. However, a minority of $19 \%$ claimed that they were not motivated by passing on anything to their children. Globally, $49 \%$ of the individuals considered that they had something valuable (i.e. capital or knowledge) to pass on to their children.

\begin{tabular}{|c|c|c|c|c|c|}
\hline & average & standard dev & $\min$ & $\max$ & $N$ \\
\hline Date of birth & 1974.18 & 19.64 & 1920 & 1988 & 243 \\
\hline Gender (0:men/1 women) & 0.59 & 0.49 & 0 & 1 & 243 \\
\hline Number of children & 2.03 & 1.06 & 0 & 5 & 56 \\
\hline $\begin{array}{l}\text { Ability to speak another foreign } \\
\text { language fluently }(0: \text { yes/1:no) }\end{array}$ & 0.55 & 0.49 & 0 & 1 & 240 \\
\hline Currently a smoker (0:yes/1:no) & 0.85 & 0.35 & 0 & 1 & 240 \\
\hline Education level & 4.16 & 1.14 & 1 & 6 & 242 \\
\hline $\begin{array}{l}\text { Monthly financial expenses } \\
\text { category ( } 1 \text { to } 6 \text { ) }\end{array}$ & 2.29 & 1.42 & 1 & 6 & 240 \\
\hline $\begin{array}{l}\text { Perception of the importance of } \\
\text { free time (ordered from } 1 \text {, no to } \\
6 \text {, of the utmost importance) }\end{array}$ & 4.12 & 1.22 & 1 & 6 & 241 \\
\hline $\begin{array}{l}\text { Financial planning horizon ( } 1 \text { to } \\
\text { 4) }\end{array}$ & 1.73 & 0.88 & 1 & 4 & 243 \\
\hline $\begin{array}{l}\text { Planning to pass on capital and } \\
\text { knowledge to children or other } \\
\text { relatives }(0: \text { yes } / 1: \text { no })\end{array}$ & 0.63 & 0.48 & 0 & 1 & 241 \\
\hline $\begin{array}{l}\text { Importance of passing on } \\
\text { capital and knowledge (from } 1\end{array}$ & 2.60 & 1.21 & 1 & 6 & 242 \\
\hline
\end{tabular}

\footnotetext{
${ }^{6}$ A total of 250 questionnaires were distributed by the Fédération des Ainés Ruraux to their members.

${ }^{7}$ I would like to thank for their support Mrs Renate Gossart, President of the association "Les panthères grises" located in Reims and Mrs Delphine Guillaume in charge of internal communication at the Fédération Nationale des Ainés Ruraux, www.ainesruraux.org.
} 
to 6)

Perception of risk attitude

3.40

1.34

1

6

243

Table 2 - Descriptive statistics of the sample

(Education level: answers from 1 (autodidact) to 6 (master's degree); Monthly financial expenses by ordered categories: 1: below $300 €$ up to 6: more than $2500 €$; Financial planning horizon ordered from 1 to 4: 1 in coming months, 4 over the next 10 years; Importance of passing on capital and knowledge: 1, null, to 6, huge; Risk attitude: ordinal value from 1, risk lover, to 6 , absolute risk rejection.)

\section{3-Results}

\section{$\underline{3.1 \text { Qualitative time preference }}$}

Questions A1 to A8 aim at testing qualitatively the time preference hypothesis by advancing two propositions. The respondent can state a preference for one or the other or can say that the two are equivalent. If the answer is indifference, it is withdrawn from the data. We only consider choices expressed as preferences. Question A1 tests the time preference hypothesis by asking the preference of individuals between 1 hour of free time now (0) and 2 hours of free time 1 year ahead (1). The average answer (indifference excluded) is 0.33 . This is significantly above zero. The idea of a trade-off between the present and the future can be accepted if a price exists, i.e. a preference of 1 hour now vs. 2 hours tomorrow. The test of equality of the A1 answer compared to a random average answer of 0.5 is rejected. However, the t-test assumes a normal distribution. This assumption is weak. We also consider a sign test (proportion below $0.5=0.64$, p-val:0.00). It confirms the previous one.

A2 is the same question with a trade-off further in the future (1 hour now vs. 5 hours in 5 years). The average answer is 0.34 . This is significantly different and lower than a random 0.5 answer.

The A1 vs. A2 test allows the checking of a difference in pricing the future. The null shows that the two means are not different. A p-value above the usual significance levels does not reject the null. The difference is not significant (p-value of the t-test: 0.00 ). This test is reliable because the A1-A2 difference is normal (Jarque-Bera statistic=64.90; p:0.00). This means that 2 hours in 1 year's time are equivalent (not different from) 5 hours in 5 years' time. The sign test gives $82 \%$ of zero differences. The implicit discount factor $(5 / 2=2.5)$ is $26 \%$ a year (for a $1-5 y$ horizon). 


\begin{tabular}{lrrrrr}
\hline & A1 corr. & A2 corr. & A1 vs. A2 & A3 corr. & A2 vs.A3 \\
\hline $\mathrm{N}$ & 209 & 217 & 209 & 191 & 187 \\
average & 0.33 & 0.34 & 0.00 & 0.45 & 0.08 \\
std dev & 0.47 & 0.47 & 0.42 & 0.55 & 0.41 \\
& & & & & \\
t-test & -5.39 & -4.94 & 0.48 & -1.38 & 2.65 \\
p-val & 0.00 & 0.00 & 0.63 & 0.17 & 0.01 \\
Sign test & & & & & \\
Proportion & 0.67 & 0.66 & 0.82 & 0.55 & 0.82 \\
below 0.5 & & & & & \\
p-val & 0.00 & 0.00 & 0.00 & 0.07 & 0.00 \\
\hline
\end{tabular}

Table 3 - Results of the block A questions (I)

(corr.: answers corrected to eliminate indifferent choices; only 0/1 answers are taken into account; question A1 is comparison of 1 extra hour of free time now or 2 hours of free time in 1 year's time; question A2 is comparison of 1 extra hour of free time now or 5 hours of free time in 5 years' time; question A3 is comparison of 1 extra hour of free time in 1 year's time or 5 hours of free time in 6 years' time; A1 vs. A2 is the difference of A1 and A2 dummy vectors (similar for A2 vs. A3)

Question A3 is the same as A2 but put forward by 1 year. The average answer is 0.45 . The t-test and the sign test show that the answer is not different compared with a random answer of 0.50. It means there is indifference between the two terms of choices suggested in question A3. We compared the answers to A2 to check whether the results are the same. A3 is significantly different from A2. According to the t-test, the hypothesis of difference is accepted, but it is rejected looking at the sign test. These results are contradictory. The statistic A3 minus A2 is normally distributed ( $\mathrm{JB}=60.16$, p:0.00); we privileged the t-test. This means that when the choice is put forward by 1 year, the preference for the time closer to the present date decreases. If the time preference had been the same, i.e. if exponential discounting were true, delaying the same choice by 1 year should have given the same result in questions A2 and A3. Here, the trade-off price is not the same. That result suggests a nonflat subjective interest rate. A decreasing curb will make the short-term side of the trade-off less attractive and place a larger weight on the long-term proposition. It is for this reason that we get an average answer of 0.45 for question A2 and above 0.37 for question A3. However, the two sets of choices are still coherent. The Spearman correlation between A2 and A3 is significant and positive (+0.65, p-val:0.00). 
Question A4 tests the curvature of the time preference function. It asks whether individuals prefer 2 hours of free time within 10 years or a package of 1 hour now and 1 hour within 20 years. If (naïve) linearity prevails, under a flat curve, the two terms are equivalent, so the answer should be the average of 0 and 1, i.e. 0.5. We get an average answer of 0.66 . The t-test against 0.5 and the sign test confirm this result to be significantly above a $50 \%$ probability. By preferring the package, individuals may have a decreasing time curve preference, i.e. a decreasing subjective price of time.

Question A5 modifies the term of the curvature. It gives a greater weight to the medium term choice (doubling it to 4 hours against 2 hours in question A4). The terms of the package remain the same. The preference for the medium-term time horizon choice (choice 0 ) increases logically with an average answer of 0.34 . Referring both to the t-test and the sign test, this is significantly lower than 0.5 . Question A5 is not meaningful in analyzing curvature because the relative terms are not comparable and not linear in the time horizon. However, it confirms that individuals are time rational. The choice (0) in A5 is logically better than the one proposed in A4. Using linear approximation and the results from A4 and A5, it means that to get indifference between $\mathrm{X}$ hours in 10 years' time and a package of 2 hours (one now and one in 20 years), we should give $(0.66-0.5) \times(4-2) /(0.66-0.34)=1.00$ hour more. This means 3.00 hours in 10 years' time compares with a set of 2 hours now and in 20 years' time.

Question A6 is another way to test the curvature. The choice is similar to A5. The package is the same, but the medium term proposal is now 2 hours within 5 years (instead of 10 years in question A4). We expected that individuals with a preference for the present would choose the first answer compared with question A4. The average value is 0.39 compared with 0.66 in question A4. This is significantly below the random average answer of 0.50 .

\begin{tabular}{lrrrrr}
\hline & A4 corr. & A5 corr. & A6 corr. & A4 vs. A6 & A5 vs. A6 \\
\hline $\mathrm{N}$ & 173 & 173 & 175 & 157 & 163 \\
average & 0.66 & 0.34 & 0.39 & 0.25 & 0.05 \\
std dev & 0.47 & 0.47 & 0.49 & 0.48 & 0.40 \\
& & & & & \\
& & & & & \\
t-test & 4.41 & -4.59 & -2.86 & 6.66 & 1.58 \\
p-val & 0.00 & 0.00 & 0.00 & 0.00 & 0.12 \\
& & & & & \\
\hline
\end{tabular}




\begin{tabular}{lccccc}
\hline $\begin{array}{l}\text { Sign test } \\
\begin{array}{l}\text { Proportion } \\
\text { below 0.5 } \\
\text { p-val }\end{array}\end{array}$ & 0.34 & 0.66 & 0.61 & 0.71 & 0.85 \\
\hline
\end{tabular}

Table 4 - Results of block A questions (II)

(corr.: answers corrected to eliminate indifferent choices; only 0/1 answers are taken into account; question A4 is comparison of 2 extra hours of free time in 10 years' time or a set of 1 hour of free time now and 1 hour of free time in 20 years' time; question A5 is comparison of 4 extra hours of free time in 10 years' time or a set of 1 hour of free time now and 1 hour of free time in 20 years' time; question A6 is comparison of 2 extra hours of free time in 5 years' time or a set of 1 hour of free time now and 1 hour of free time in 20 years' time; A4 vs. A6 is the difference of A4 and A6 dummy vectors (similar for A5 vs. A6)

We will now consider the difference A4 vs. A6; it is normally distributed (JB=10.14, $\mathrm{p}: 0.01)$. The difference between A6 and A4 is significant. The results are not the same as comparing A6 answers to those to the A5 question. When testing the hypothesis of different means between A6 and A5, we reject it. Using a sign test, we have a different conclusion with an average probability of an identical median of $85 \%$. We will accept the conclusion of the ttest on the basis that data are normally distributed $(\mathrm{JB}=78.82, \mathrm{p}: 0.00)$ and that the sign test is less robust. This means that 4 hours in 10 years' time are equivalent to 2 hours within 5 years. The psychological (annual) interest rate for the 5-10 year horizon that emerges is, therefore, $14.9 \%$. This is lower than the $26 \%$ average subjective rate for the $1-5$ year horizon.

We can mix the A4 and A6 results and use a linear approximation to find indifference between 2 hours in the future and the package $(1 \mathrm{~h}$ now $+1 \mathrm{~h}$ in 20 years' time). We have: $(0.66-0.5) \times(10-5) /(0.66-0.39)=2.96$ years. This means that 2 hours in 7.96 years' time are equivalent to the package and the package is equivalent to 3.00 hours in 10 years' time (see above). The variation between 7.96 and 10 years is 2.04 years for an increase of 1.00 hours of free time.

Question A7 is identical to A4 but presented in reverse order. The idea here is to test if respondents are coherent. The answers should be strictly opposite to those of A4. We inverted the A7 answers to get an average value of 0.54 . This is not significantly different from 0.5 (in contrast with the A4 question). The test of the difference between A4 and inverted A7 shows a significant and unexpected difference according to the t-test. However, the t-test should be disregarded insofar as the A4 vs. inverted A7 variable is not normally distributed (JarqueBera=1.53, p:0.46). The sign test shows no significant difference. The Spearman rank 
correlation coefficient between A4 and inverted A7 is 0.43 . This is significantly positive $(\mathrm{p}=0.00)$. Hopefully, the same respondents are giving the same answer to similar questions in the questionnaire.

Question A8 is a test of altruism. After correction for indifference, the average value is 0.72 , closer to 1 (altruistic attitude) than to 0 (personal individualism). The test vs. a random 0.5 value is significant. The Spearman coefficient was calculated to cross with curvature (question A4). The coefficient is 0.01 . This is non significant $(\mathrm{p}=0.30)$. Altruism does not seem to be linked with curvature, i.e. temporality in the subjective price of time. These are two separate dimensions of human behavior.

\begin{tabular}{lrrr}
\hline & A7 inv. & A7inv. vs. A4 & A8 corr. \\
\hline $\mathrm{N}$ & 177 & 157 & 183 \\
average & 0.54 & 0.14 & 0.72 \\
std dev & 0.50 & 0.52 & 0.45 \\
& & & \\
t-test & 1.28 & -3.34 & 6.47 \\
p-val & 0.20 & 0.00 & 0.00 \\
Sign test & & & \\
Proportion below & 0.55 & 0.71 & 0.28 \\
0.5 (or equal to 0) & & & \\
p-val & 0.11 & 0.00 & 1.00 \\
\hline
\end{tabular}

Table 5 - Results of the block A questions (III)

(inv.: answers are corrected to eliminate indifferent answers and are inverted; corr.: corrected to eliminate indifferent choices; only $0 / 1$ answers are taken into account; question $\mathrm{A} 4$ is comparison of 2 extra hours of free time in 10 years' time or a set of 1 hour of free time now and 1 hour of free time in 20 years' time; question A5 is comparison of a set of 1 extra hour of free time now and 1 hour of free time in 20 years' time or 2 hours of free time in 10 years' time; question 8 is, in 10 years' time, comparison of 2 hours of extra free time for yourself or to get in 10 years' time a set of one hour of free time for yourself and 1 hour of free time for one of your relatives)

\subsection{Quantitative time preference evaluation}

The direct price of time is tested through questions B1 to B6 considering the "price" of one hour of "free time" at different time horizons 1y, 5y, 10y, 20y, 30y and 50y. A measure of the subjective price of time is built considering the increase in the relative value of one hour of free time now and one hour later. If the subjective price of that hour increases, it 
means that the time has a cost. We compared the individual answers to question B1 with the average answer to questions B2 to B6. If an individual answers, for instance, 2 to question B1, it means he gives a value of 1 to $2 \mathrm{~h}$ of free time in 1 year in the future compared with for one hour of free time now. If the average answer to the same question, but deferred forward in time (question B2), is 4, it means than the relative ratio of his personal time value is 6 to 9 hours compared to one hour now. We calculated the (possibly) negative slope of the subjective interest rate as the difference between the B1 answer and the average relative ratio resulting from questions B2 to B6. For instance, the previous respondent will yield a value of -2 (i.e. 2 at question B1 minus 4 at question B2); this shows a time preference attitude with deferred free time having less value than a near current free time opportunity. If the average difference is negative, this indicates globally a positive price for time (or a preference for immediacy). Looking at the answers, the average value of the subjective price for time indicator is effectively negative (-1.49) and significantly different from null. The answer is the same with the "informed" set of respondents. Questions C6 to C11 correspond exactly to questions B1-B6. The answer to question C6 was compared in the same way to the average answers considering a deferred horizon from 5 to 50 years (i.e. questions $\mathrm{C} 7$ to $\mathrm{C} 11$ ). The average value of the informed price of time indicator is significantly negative (-1.48).

\begin{tabular}{|c|c|c|c|c|}
\hline Questions & $B 1$ & $\begin{array}{l}\text { Average time } \\
\text { value } B 2 \text { to } B 6\end{array}$ & C6 & $\begin{array}{l}\text { Average time } \\
\text { value C7-C11 }\end{array}$ \\
\hline $\mathrm{N}$ & 228 & 207 & 225 & 207 \\
\hline average & 2.24 & -1.49 & 2.23 & -1.48 \\
\hline std dev & 1.65 & 1.65 & 1.70 & 1.75 \\
\hline t-test & & -13.04 & & -12.14 \\
\hline p-val & & 0.00 & & 0.00 \\
\hline
\end{tabular}

Table 6 - Results of block B and C questions

(Each individual question is comparison of one extra hour of free time now and its equivalent number of hours of free time in respectively 1 year, 5 years, 10 years, 20 years, 30 years and 50 years' period of time; answers are pre-coded within 9 ordered ranges; the set of questions B1-B6 is asked before delivering new information, the set of questions C6-C11 is asked after; the delivery of new information; new information is the expectancy life table of French population and the calculation by the respondent himself of his expected date of death; average time value is for each individual the difference between the average answer to question $\mathrm{B} 2$ to $\mathrm{B} 6$ and his answer to question $\mathrm{B} 1$, a negative figure means an increase of the value of time with a longer horizon; same for average answers to deferred horizon C7-C11 and question C6) 
When informed of his true average life expectancy, the individual does not seem to modify his answer regarding his subjective price of time. The score decreases from 2.24 (question B1) to 2.23 (question C6). The difference between questions B1 and C6 is not significant ( $\mathrm{t}$-test=-0.15, p:0.88). The same is true for the subjective price of time before and after ( $\mathrm{t}$-test=-0.13, p:0.89). The two scores of subjective price of time show a strong correlation (Pearson correlation of +0.75 , p:0.00). Salient and objective information given on time delay does not change the structure of the answers. We draw the conclusion that objective information on time does not modify its individual perception. Contrary to Zauberman et al. (2009) our result does not seem to be contaminated by a time perception effect. The decreasing slope of the individual term structure of psychological rates seems strong.

\section{4-The term structure of subjective time preference}

We calculated the average answer to the subjective price of time. Each question can be answered from checking ordinal values from 1 (a future free hour has a lower price than the current free time hour) up to 9 (i.e. one free time hour in the future has less value than 45 seconds today). Answer 1 is economically irrational in terms of time preference. It means a preference for the future compared to the present. It could also mean that the respondent did not understand the question.

The integer answers from 1 to 9 are trade-off relative values. The average ordinal answers to each question have been converted into subjective interest rates using the midrange value. For instance, if a given individual answers 4 to question B2, he says that he will ask for between 6 and 12 hours of future free time 5 years ahead to be equivalent to one hour just now. Taking the mid-point of 9 hours in 5 years' time, we derive an implicit subjective price of time of $55.18 \%$ per year. ${ }^{8}$

Taking the average value of the choices of the individuals, we obtain a collective time value preference. Table 7 shows the average answers with regard to the 6 time horizons. The structure of the average psychological interest rates clearly decreases with the time horizon. The short-term rate is $135.31 \%$ ( 1 year ahead); it decreases to $5.80 \%$ (50 years horizon). The

\footnotetext{
${ }^{8}$ Solving the equation $(1+x)^{5}=9$.
} 
data collected after delivering objective information on life expectancy are similar. The term structure of psychological interest rates decreases from $117.53 \%$ to $5.97 \%$.

\begin{tabular}{|c|c|c|c|c|c|c|}
\hline Horizon (years) & 1 & 5 & 10 & 20 & 30 & 50 \\
\hline \multicolumn{7}{|l|}{ Panel A Before information } \\
\hline Av. ordinal answer & 2.3904 & 2.9248 & 3.4509 & 4.0045 & 4.3756 & 4.9074 \\
\hline Av. number of future hours for one & 2.4759 & 3.8119 & 6.2545 & 9.0360 & 12.0045 & 16.2593 \\
\hline \multicolumn{7}{|l|}{ free time hour now } \\
\hline Implicit subjective interest rate & 1.4759 & 0.3069 & 0.2012 & 0.1163 & 0.0864 & 0.0574 \\
\hline \multicolumn{7}{|l|}{ Panel B After information } \\
\hline Av. ordinal answer & 2.4044 & 2.9381 & 3.4395 & 3.9452 & 4.3052 & 4.9761 \\
\hline Av. number of future hours for one & 2.5111 & 3.8451 & 6.1973 & 8.7260 & 11.4413 & 16.8086 \\
\hline \multicolumn{7}{|l|}{ free time hour now } \\
\hline Implicit subjective interest rate & 1.5111 & 0.3091 & 0.2001 & 0.1144 & 0.0846 & 0.0581 \\
\hline
\end{tabular}

Table 7 - Estimate of average subjective interest rates

(Average ordinal: average of answers from 1 to 9 without corrections of outliers; Average number of future hours: number of future hours equivalent to one hour now calculated from the average answer by interpolating the mid-range of the ordinal answer (see Table A2 in Annex); implicit subjective rate: annual equivalent rate calculated using the maturity and the ratio of the number of future hours compared to one hour now; before information relates to block B questions; after information relates to block $\mathrm{C}$ questions; information delivered between the two is the statistical mortality table and the average life expectancy of the respondent)

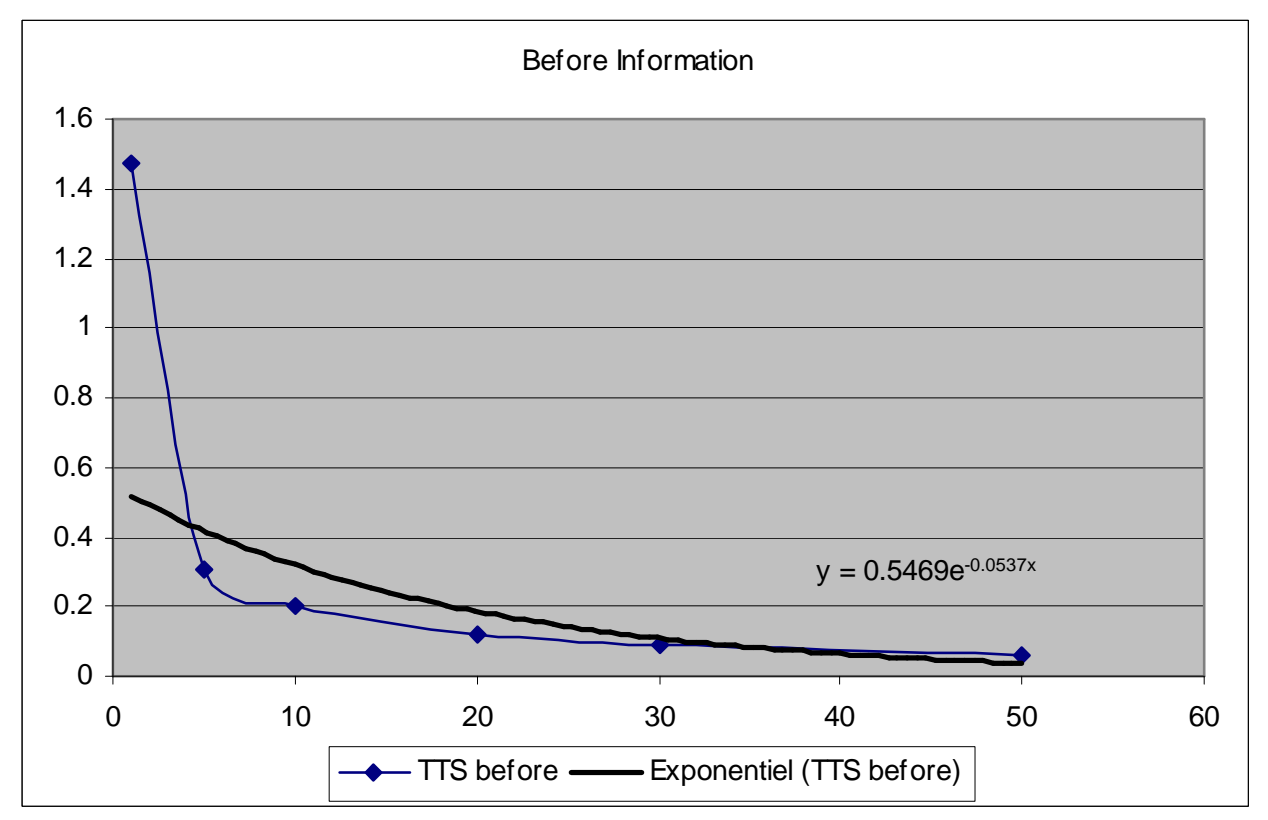


Figure 1 - Average estimate of subjective interest rates (Before information)

(Source: Table 3; fitted using an exponential model)

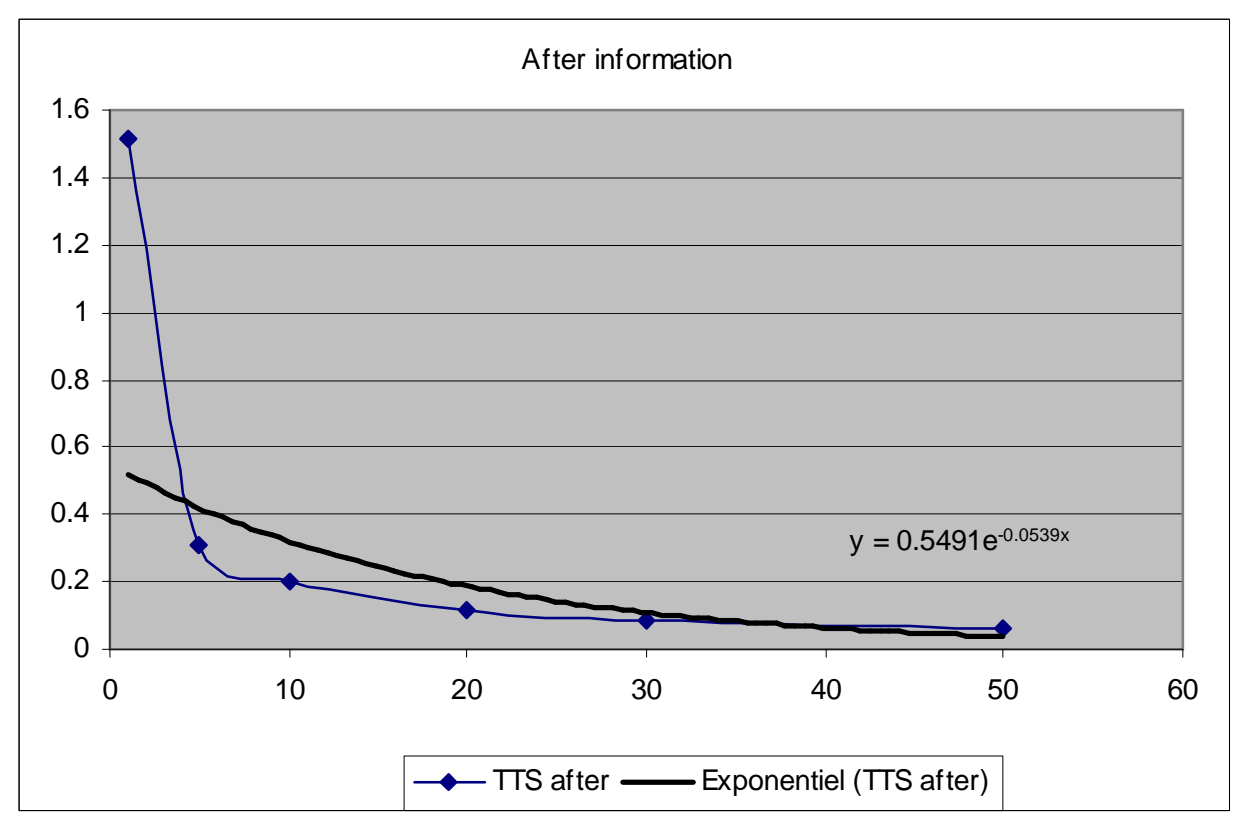

Figure 2 - Average estimate of subjective interest rates (After information)

(Source: Table 3; fitted using an exponential model)

The fitted term structure of subjective interest rates is calculated using an exponential model: $r(t)=b \cdot a^{t} .{ }^{9}$ The estimation is performed on average data from Table 7 . The $b$ coefficient is the instantaneous subjective interest rate to future free time one second in the future. The fitted values are 55\% (before and after information). The subjective price of time is characterized by a negative slope in the term structure curve. The log of the slope is a yearly $-5.37 \%$ (before information) and $-5.39 \%$ (after).

Looking at each individual, we transform his ordinal answer to annual implicit subjective rates using a correspondence table (see Annex). We corrected outliers particularly for wrong answers at question 1 about the relative ratio of one hour in one year. Wrong answers above 4 at question B1 (C6) will bias upward the implicit rates and result in abnormally high implicit rates. This may be due to a misunderstanding of the question. We decided not to remove these answers but to limit the maximum subjective rate to $500 \%$. Descriptive statistics of the term structure of subjective interest rates of each respondent are given in Table 8 .

\footnotetext{
${ }^{9}$ One parameter hyperbolic fitting gives poor results.
} 


\begin{tabular}{lccccc}
\hline Variable & $N$ & average & std. dev. & Minimum & Maximum \\
\hline AV1 & 228 & 1.397184 & 1.713725 & 0.001000 & 5.000000 \\
AV5 & 226 & 0.320404 & 0.339724 & 0.001000 & 1.390116 \\
AV10 & 224 & 0.184333 & 0.167918 & 0.001000 & 0.546000 \\
AV20 & 222 & 0.103912 & 0.084450 & 0.001000 & 0.243382 \\
AV30 & 221 & 0.074331 & 0.057571 & 0.001000 & 0.156298 \\
AV50 & 216 & 0.048872 & 0.035622 & 0.001000 & 0.091043 \\
\hline
\end{tabular}

Table 8 - Descriptive statistics for individual subjective interest rates

(Time horizon 1y, 5y, 10y, 20y, 30y, 50y; source: relative price ratios from questions B1 to B6, converted into annual interest rates using the correspondence table A2 in Annex)

Looking at average values, the term structure seems clearly negative. It starts from an average $140 \%$ for the psychological interest rate for the 1 year horizon. This high figure is partly explained by possible errors in understanding the question and by outlier answers that have not been removed. At the end of the term structure, the rate is $4.9 \%$ for a 50 year horizon.

For each individual, we have a six point estimate of his psychological time preference structure. We fitted each individual term structure using an exponential two variable model. Each individual's characteristic time preference structure can be defined using a couple of parameters, which are the intercept instantaneous interest rate and the slope. Over the whole sample, the average estimated parameter for the slope is 0.96 (which corresponds to a log of the slope of $-3.60 \%$ yearly). The average estimates intercept of the exponential model is 0.53 (i.e. a 53\% instantaneous forward interest rate). Results are similar when considering the answers to the $\mathrm{C}$ questions. ${ }^{10}$

When we regress the individual $b_{i}$ estimates of the intercepts and the individual slopes $a_{i}$, we obtain a -0.567 coefficient of correlation. Among individuals, if someone has a strong immediate time preference, his long-term time trade-off is smoother with a lower negative slope with time horizon. This relationship is confirmed even if we add new information about the "true and average" life expectancy. This raw correlation indicates the existence of a relationship between the instantaneous forward subjective rate of the two parameters and the

\footnotetext{
${ }^{10}$ These questions are answered after giving objective information to respondents regarding their life expectancy. The average slope parameter is also 0.96 and the average intercept is 0.50 .
} 
slope of the term structure of time value; however, it does not tell us anything about the form of the relationship. The linear form is not the best one. We also tested a log-log form. That gives a better fit with an $\mathrm{R}^{2}$ value of 0.573 (correlation of -0.76 , see table 9).

\begin{tabular}{lrr}
\hline & $\beta$ & $\alpha$ \\
\hline Estimated coefficient & -0.01322 & -0.0663 \\
$\mathrm{p}$-value & 0.00 & 0.00 \\
$\mathrm{R}^{2}$ & 0.5727 & \\
\hline
\end{tabular}

Table 9 - Log-log relationship between individual slope and intercept estimates of subjective term structure discount

(Relation is $\log \left(a_{i}\right)=\alpha+\beta \log \left(b_{i}\right)$ where $a_{i}$ are term structure slope estimates; $b_{i}$ are instantaneous forward rate estimates; $r(t)=b \cdot a^{t} ; \mathrm{N}=216$ )

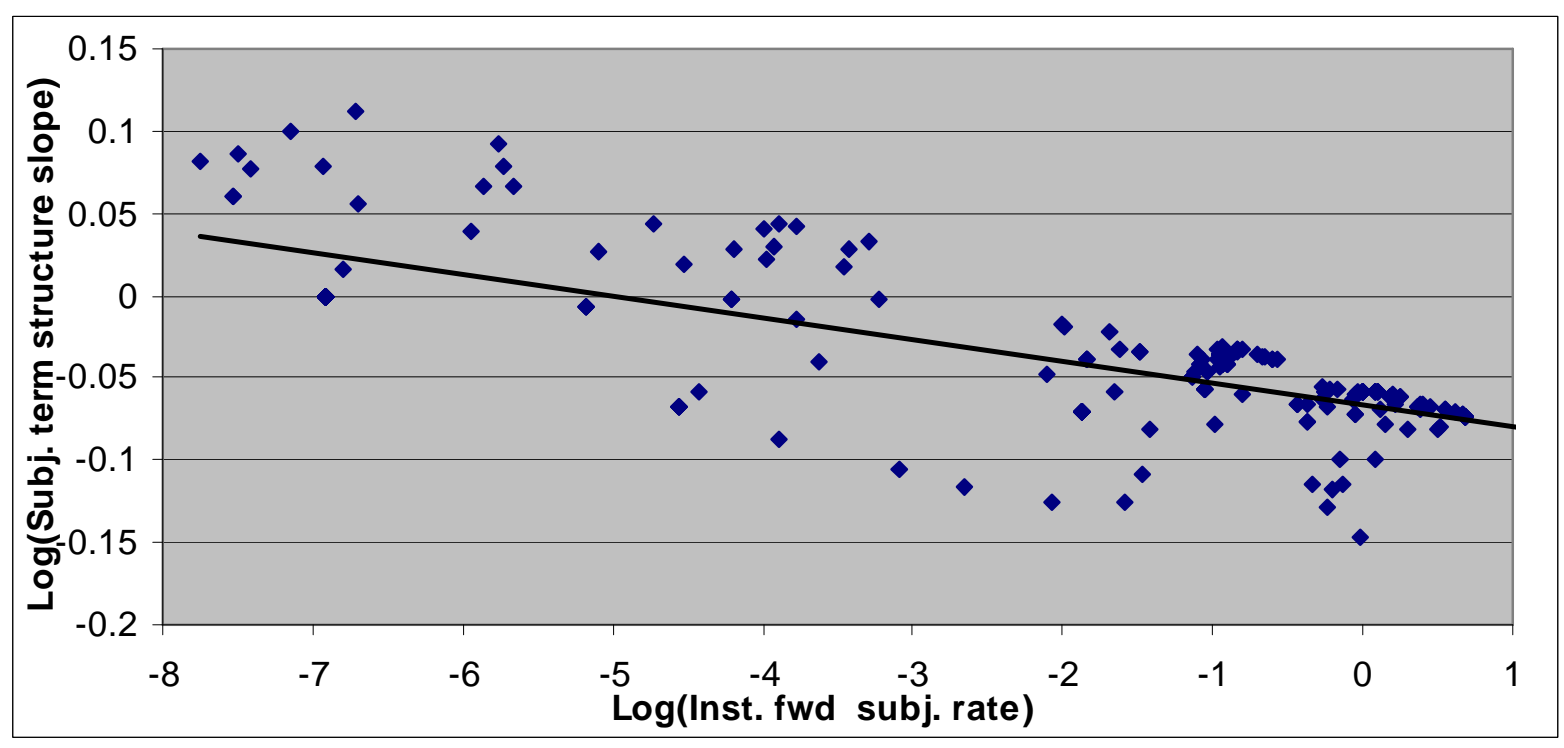

Figure 3 - Log-log relationship between individual intercepts and slopes

We can draw the two following conclusions:

- The individual's term structure of subjective psychological interest is decreasing. They are characterized by a couple of parameters corresponding to the instantaneous forward interest rate and the decreasing slope of his personal term structure of interest rate.

- A negative relationship exists between the two parameters defining the term structure of subjective rates: an individual with a strong short-term time preference experiences a more negative slope. He penalizes the deferred future relatively less compared with an individual whose instantaneous short-term interest rate is small. 
As a result, a behavioral "law" may be formulated: those with a high immediate time preference have a relatively less demanding time preference in the deferred future. The original time preference hypothesis needs to be conceptualized at a deeper level: the strength of that preference does not result in an equal pressure directed toward the future. Time has a psychological price, but a term structure exists that unifies the relative prices. This defines a "balancing pressure law": A balancing mechanism spreads over the horizon the pressure for a time preference. Regarding the subjective price of time, when someone asks for a lot in the very near future, he asks for a relatively lesser amount in the long-term future.

\section{$\underline{\text { Influence of information on subjective interest rates }}$}

Introducing information refers to questions $\mathrm{C} 5-\mathrm{C} 11$, which are similar to questions B1-B6. Between the two sets of questions, the respondent is informed of his average statistical life expectancy as calculated from the official mortality table.

We form the differences in the subjective interest rates for each horizon of 1 year, 5 years, 10 years, 20 years, 30 years and 50 years. These differences are subjective interest rates calculated before and after new information on the true average life expectancy. We cross these differences with individual characteristics. We first used a simple univariate regression and then a system of joint estimate to see whether individual features may explain global moves in attitude toward time preference. The results were negative. None of the individual characteristics appeared to explain changes in attitude toward time. These variables are the individual's characteristics. A multivariate SUR model of the difference of subjective rates before and after information for horizons of 1, 5, 10, 20, 30 and 50 years was estimated with 5 endogenous variables. This gave the same inconclusive results that no individual characteristics would influence changes in subjective interest rates. The effect of new information on the shape of the term structure of subjective interest rates seems to be random and on average null.

We analyzed directly the influence of information on the value of the two parameters designing the individual term structure data. After information, the average of individual intercepts decreases (50\% vs. 53\%) and the log of the slope remains on average the same ($3.60 \%$ after vs. $-3.60 \%$ before). A t-test of the difference between the intercepts before and 
after rejects the hypothesis of different individual values (t-test=1.26, p-val: 0.21 ).A test of the difference between the $a_{i}$ slope after and before was performed. It also rejects the hypothesis of different means (t-test=1.46, p-value:0.51). We do not confirm a significant effect of time perception which may alter the decreasing slope of the psychological intertemporal discounting. Our results are opposed to those of experiments 3 and 4 made by Zauberman et al. (2009).

\section{Modeling the term structure of subjective interest rates}

We characterized the subjective term structure by an intercept (immediate time preference) and a slope. We first tested whether a relationship between the intercept interest rate or the slope, on the one hand, and 16 specific determinants, on the other, may exist. These larger regressions show no strong or significant relationships. We used restricted models with 5 and 3 explicatives. Results are given in Table 10.

\begin{tabular}{|c|c|c|c|c|c|c|c|}
\hline $\begin{array}{l}\text { Dependent } \\
\text { variable }\end{array}$ & Constant & Gender & $\begin{array}{l}\text { Risk } \\
\text { aversion }\end{array}$ & $\begin{array}{l}\text { Life } \\
\text { expectancy }\end{array}$ & Smoker & Education & $F$ \\
\hline $\begin{array}{l}\text { Individual } \\
\text { slope }\end{array}$ & 0.9577 & 0.0144 & -0.0025 & 0.0020 & -0.0150 & 0.0058 & 2.47 \\
\hline p-val & 0.00 & 0.03 & 0.31 & 0.37 & 0.08 & 0.05 & 0.03 \\
\hline $\begin{array}{l}\text { Individual } \\
\text { intercept }\end{array}$ & 0.2220 & -0.2861 & 0.0851 & 0.0035 & & & 4.44 \\
\hline p-val & 0.24 & 0.00 & 0.01 & 0.20 & & & 0.00 \\
\hline
\end{tabular}

Table 10 - Determinants of the term structure parameters

(OLS regression; gender is a dummy; risk aversion is S23 variable individual perceived risk attitude scaled from 1 to 6; statistical life expectancy is calculated using the INSEE expectancy table; smoker is a dummy; education is S14 variable from 1(low) to 6(high level))

The slope of the individual subjective price of time does not seem to depend on any individual characteristics, but gender. The steepness of the decreasing term structure of personal discount rates is lower for women. The regression of the slope on exogenous variables such as risk aversion or life expectancy is non-significant. Education and smoking status seem to play a role. Smoking is a characteristic already identified in the literature. Ceteris paribus, it adds subjective value to long term choices. If we accept the hypothesis that smoking status is a proxy for the individual's perceived life expectancy and wealth we fin 
results in line with, for instance Ohmura et al. (2005). On the other hand, the level of the intercept is a psychological piece of data which interacts significantly with risk aversion and gender. This suggests the need for further analysis because these two individual characteristics may be related (see below). The level of intercept does not depend on life expectancy. The absence of influence of the life expectancy in the two determinants of the individual subjective value of time is important. Because the sample is composed with two different groups of people with respectively high (students) and low life expectancy (retired people) we compared the values of the two sets of slopes and intercepts defining the time attitude. The coefficients $a_{i}$ and $b_{i}$ do not follow a normal distribution ${ }^{11}$. However a test of difference between means is significantly rejected either with regard to the slope coefficients or the intercept coefficients.

\begin{tabular}{lrr}
\hline & \multicolumn{1}{c}{$\begin{array}{l}\text { Retired } \\
\text { people }\end{array}$} & Students \\
\hline $\mathrm{N}$ & 33 & 183 \\
Term structure slope & 0.9573 & 0.9659 \\
Average & -1.06 & $(0.29)$ \\
t-test of difference (p-val) & 0.0430 & 0.0457 \\
Standard deviation & 0.2038 & 1.0464 \\
Skewness & 1.2942 & 1.1731 \\
Kurtosis & 0.9341 & 0.9352 \\
$1^{\text {st }}$ quartile & 0.9975 & 0.9975 \\
$3^{\text {Id }}$ quartile & & \\
Instantaneous future time & & \\
preference & 0.4033 & 0.5530 \\
Average & -1.57 & $(0.12)$ \\
t-test of difference (p-val) & 0.4818 & 0.6408 \\
Standard deviation & 1.6296 & 1.8695 \\
Skewness & 2.7053 & 6.0949 \\
Kurtosis & 0.0104 & 0.0192 \\
$1^{\text {st }}$ quartile & 0.4942 & 0.9549 \\
$3^{\text {rd }}$ quartile & & \\
\hline Table 11 - Difference of subjective & & \\
\hline
\end{tabular}

Table 11 - Difference of subjective term structure parameters between two sub-samples $\left(a_{i}\right.$.are term structure slope estimates; $b_{i}$ are instantaneous forward rate estimates; individual estimates of $r(t)=b . a^{t}$ where $r(t)$ are implicit subjective discount rates based on the B1-B6 answers to the questionnaire)

Contrary to Von Mises' hypothesis of dependency with life expectancy, our result supports the following conclusion: The term structure of the personal price of time is an invariant psychological feature with no tempus fugit effect.

\footnotetext{
${ }^{11}$ The Jarque-Bera test shows a significant departure from the normal distribution.
} 


\section{Analysis of risk aversion}

Risk aversion is tested through three questions. The first two questions compare a package resulting from playing a lottery and a certain value. Question S21 tests whether the expected uncertain value above the certain one is preferred. Question S22 is the same but the expected value is equal to the certain value. Risk averse people should choose the first answer (i.e. 0 compared to 1 ) for this latter question. The average answer to $\mathrm{S} 21$ is 0.36 . This is significantly different from a random 0.5 answer. Looking at question S22, the average answer is 0.14 . This is also significantly different from 0.5 . This latter choice is closer to 0 than to 1 ; i.e. it means that the certain value is preferred compared with playing the lottery. This is coherent with the risk aversion hypothesis, which asserts that the certain value is definitely preferred when the expected value of playing the lottery is equal to the certain value. The difference between the two answers $\mathrm{S} 21-\mathrm{S} 22$ is positive $(+0.21)$ and significant.

\begin{tabular}{lrrr}
\hline & S21corr. & S22 corr. & S21 vs. S22 \\
\hline $\mathrm{N}$ & 229 & 236 & 224 \\
average & 0.36 & 0.14 & 0.21 \\
std dev & 0.48 & 0.35 & 0.54 \\
& & & \\
t-test & -4.33 & -15.95 & 5.91 \\
p-val & 0.00 & 0.00 & 0.00 \\
& & & \\
Sign test & & & 0.28 \\
$\begin{array}{l}\text { Proportion below 0.5 } \\
\text { (above 0) }\end{array}$ & 0.64 & 0.86 & \\
p-val & & & 0.00 \\
\hline
\end{tabular}

Table 12 - Risk aversion

(corr.: corrected to eliminate indifferent answers; question S21 is a comparison of a certain value of 10 euros and a lottery with $50 \%$ chance to earn 25 euros and $50 \%$ chance to earn nothing; question S22 is a comparison of a certain value of 20000 euros and a lottery with 50\% chance to earn 50000 euros and 50\% chance to earn nothing; 0 is certain value, 1 is lottery)

We crossed the perception of risk as declared by individuals (question S23) with the answers to the lottery questions S21 and S22. We expected that the self-perception of risk attitude would be coherent with the risk aversion as measured by the answers about the two lotteries. The answers to question S23 range from 1 to 6 , with an ordinal value increasing with 
risk aversion starting from a risk lover's attitude (1) to that of a risk avoider (6). Rational individuals when choosing the lottery will be conscious of taking a risky position compared with a no-risk choice. The S23 measurement increases with risk aversion. A logit regression of S21 and S22 shows a strongly negative coefficient linked to the risk attitude of S23. The coefficients are negative: an increase in risk aversion decreases the choice of the lottery and increases the probability of choosing the certain value. The individual's perception of his risk aversion is coherently linked with the lotteries (see Table 13). Individuals are coherent when answering with regard to risk.

\begin{tabular}{llllll}
\hline & Estimated coef & p-val & Pseudo $R^{2}$ & LR & p-val \\
\hline $\begin{array}{l}\text { Lottery S21 } \\
\begin{array}{l}\text { S23 variable } \\
\text { constant }\end{array}\end{array}$ & $\begin{array}{l}-0.70 \\
\text { yes }\end{array}$ & 0.00 & 0.17 & 40.23 & 0.00 \\
$\begin{array}{l}\text { Lottery S22 } \\
\text { constant }\end{array}$ & $\begin{array}{l}-0.42 \\
\text { yes }\end{array}$ & 0.00 & 0.04 & 8.35 & 0.00 \\
\hline
\end{tabular}

Table 13 - Relation between risk lottery games and perception of risk attitude

(Logit model with constant; explained variables are lotteries S21 and S22, each with a 0/1 answer; explicative S23 variable is the perception of one respondent's attitude toward risk from an ordered scale between 1 (risk lover) to 6 (risk averter); LR: likelihood ratio)

An individual's risk attitudes are crossed with an individual's characteristics to explain risk aversion. As explanatory variables, we introduce cultural and educational elements. A binary dummy sets whether the mother tongue of the respondent is French or not. The same question is asked regarding the native language of his father and his mother. A dummy variable sets whether the location of the individual's birthplace is France or not. We also introduced a similar binary variable in order to find out whether the birthplace of his father (and/or his mother) is France.

\begin{tabular}{lllllll}
\hline Variables & $\begin{array}{l}\text { S21 risky } \\
\text { lottery }\end{array}$ & p-value & $\begin{array}{l}\text { S22 risky } \\
\text { lottery }\end{array}$ & p-value & $\begin{array}{l}\text { S23 risk } \\
\text { perception }\end{array}$ & $p$-value \\
\hline S2 - Gender & -0.69 & $0.00^{* * * *}$ & 0.03 & 0.92 & 0.74 & $0.00^{* * * *}$ \\
S12 - Smoker & -0.44 & $0.04^{* *}$ & -0.70 & $0.01^{* *}$ & 0.11 & 0.60 \\
S14 - Education & 0.11 & 0.22 & -0.31 & $0.02^{* *}$ & -0.05 & 0.46 \\
S15 - Employed/not & -0.63 & 0.40 & 0.75 & 0.45 & -0.08 & 0.89 \\
S16 -Financial & 0.06 & 0.55 & 0.01 & 0.94 & -0.03 & 0.70 \\
$\begin{array}{l}\text { expenses } \\
\begin{array}{l}\text { S18- Financial } \\
\text { planning horizon }\end{array}\end{array}$ & -0.10 & 0.35 & -0.26 & 0.11 & -0.11 & 0.19 \\
\hline
\end{tabular}




\begin{tabular}{lllllll}
\hline $\begin{array}{l}\text { S19 - Passing } \\
\text { something on to heirs }\end{array}$ & 0.44 & $0.05^{*}$ & 0.48 & $0.09^{*}$ & -0.22 & 0.21 \\
$\begin{array}{l}\text { S20 - Size of personal } \\
\text { capital }\end{array}$ & -0.06 & 0.55 & 0.05 & 0.62 & -0.12 & 0.11 \\
$\begin{array}{l}\text { French native } \\
\text { language/not }\end{array}$ & -0.01 & 0.98 & 0.26 & 0.51 & 0.15 & 0.60 \\
$\begin{array}{l}\text { Father's French native } \\
\text { language }\end{array}$ & 0.25 & 0.63 & -0.04 & 0.95 & -0.74 & $0.06^{*}$ \\
$\begin{array}{l}\text { Mother's French } \\
\text { native language }\end{array}$ & -0.35 & 0.48 & 0.23 & 0.72 & 0.79 & $0.03^{* *}$ \\
$\begin{array}{l}\text { Birthplace } \\
\text { (France/not) }\end{array}$ & -0.03 & 0.92 & 0.13 & 0.72 & -0.26 & 0.34 \\
$\begin{array}{l}\text { Father's birthplace } \\
\text { (France/not) }\end{array}$ & 0.04 & 0.91 & 0.75 & 0.20 & 0.25 & 0.45 \\
$\begin{array}{l}\text { Mother's birthplace } \\
\text { (France/not) }\end{array}$ & -0.16 & 0.66 & -1.18 & $0.02^{* *}$ & -0.21 & 0.43 \\
$\begin{array}{l}\text { Life expectancy } \\
\text { LR }\end{array}$ & 0.01 & 0.52 & 0.00 & 0.96 & -0.01 & 0.42 \\
pseudo-R2 & 18.08 & 0.20 & 11.45 & 0.65 & 57.81 & 0.00 \\
\hline
\end{tabular}

Table 14 - Determinants of risk attitude

(Dependent variables: playing the lottery S21 and S22, probit model; dependent variable S23 risk perception, ordered probit model)

Looking at S21 lottery, only two variables seem to explain the risk attitude: gender and the wish to pass on something to children. Women were found to choose the certainty choice; the lower the wish to pass on something to children, the greater the probability of choosing the lottery. The other variables are not significant, especially life expectancy.

Looking at the S22 lottery, the probability of choosing the lottery instead of certainty is negatively influenced by non smoker status, by education, and by the fact that the mother was born in France. Life expectancy is not significant. These two probit regressions are globally very poor considering the whole set of explanatory variables.

The S23 self-perceived risk attitude is explained by gender (women are prone to reject risky choices), and by the fact that the mother's language is French: if yes, the risk is rejected. Conversely, if the father's native language is French, individuals are greater risk lovers. Globally the risk attitude is a personal psychological feature and appears to have no economical or social determinants such as wealth, employment status or education level. In particular, risk attitude does not seem to depend on life expectancy. However, it is linked with gender and, at a lower level, with cultural variables such as the fact that the native language of the father and the mother is not the same. 
Theses results identify gender as a determinant variable in risk aversion attitude. This has to be crossed with the result displayed Table 10 where both gender and risk aversion appears also to explain significantly the characteristics of the subjective discount rate of individuals. We face an endogenuity problem because risk aversion itself is linked with gender.

\section{5-Determinants of time preference}

We will now try to explain the determinant variables of the individual time preference curve.

\section{Determinants of relative prices of time}

We can analyze directly the individual relative prices of time resulting from a direct estimate by an individual. We consider here 6 individual logit models to explain each of the variables B1 to B6. We used a large set of control variables. Results are shown in table A3 in annex. Gender is highly significant in any of the 6 models, Risk aversion is moderately significant. However because of correlation between risk aversion and gender, we cannot statute. Another reason to disregard individual Logit model is that individuals are globally giving a subjective value to time on the whole horizon they consider. They use a term structure of interest rate which is global..

We used a conversion factor that eliminates outliers to convert the B1-B6 and the C6C11 answers in order to make explicit a continuous trade-off between extra hours of free time in future periods. We obtain different values of the implicit subjective interest rate for each individual. The transformation of ordered answer into subjective rates chraccterised by positive and continuous values allows ti use a paramtric modeling with a continuous dependant variable Reference to implicit interest rates allows a limiting of the effect of outliers particularly for answers to question B1. We performed a system of 6 simultaneous equations to model the individual subjective discount rates for 1, 5, 10, 20, 30 and 50 years horizons. The identified endogeneity between explicative variable is modelized with a seventh 
parametric equation explaining the risk aversion attitude by gender. We estimated a 7 equations system.

\begin{tabular}{lllllll}
\hline \multicolumn{7}{l}{ Independent variables } \\
\hline $\begin{array}{l}\text { Dependant } \\
\text { variables }\end{array}$ & Constant & Gender & $\begin{array}{l}\text { Risk } \\
\text { aversion }\end{array}$ & $\begin{array}{l}\text { Life } \\
\text { expectancy }\end{array}$ & $\begin{array}{l}\text { Planning } \\
\text { horizon }\end{array}$ & $\mathrm{R} 2$ \\
1-AV1 1y & 0.36 & -0.68 & 0.26 & 0.01 & 0.02 & 0.05 \\
p-val & 0.55 & $0.00^{* * *}$ & $0.00^{* * *}$ & 0.18 & 0.90 & \\
2-AV5 5y & 0.15 & -0.13 & 0.04 & 0.00 & 0.00 & 0.04 \\
p-val & 0.22 & $0.01^{* * *}$ & $0.05^{* *}$ & 0.14 & 0.96 & \\
3-AV10 10y & 0.10 & $-0.08^{* * *}$ & 0.02 & 0.00 & -0.00 & 0.06 \\
p-val & $0.08^{*}$ & $0.00^{* * *}$ & $0.03^{* *}$ & 0.10 & 0.83 & \\
4-AV20 20y & 0.07 & $-0.04^{* * *}$ & 0.01 & 0.00 & -0.00 & 0.06 \\
p-val & $0.01^{* *}$ & $0.00^{* *}$ & 0.11 & 0.12 & 0.98 & \\
5-AV30 30y & 0.05 & -0.03 & 0.00 & 0.00 & -0.00 & 0.06 \\
p-val & $0.01^{* *}$ & $0.00^{* *}$ & 0.19 & $0.06^{*}$ & 0.96 & \\
6-AV50 50y & 0.03 & -0.01 & 0.00 & 0.00 & -0.00 & 0.07 \\
p-val & $0.02^{* *}$ & $0.01^{* *}$ & 0.10 & $0.03^{* *}$ & 0.43 & \\
& & & & & & \\
7-Risk & 2.82 & 0.87 & & & & \\
aversion & & & & & & \\
p-val & $0.00^{* * *}$ & $0.00^{* * *}$ & & & & \\
\hline
\end{tabular}

Table 15 -Determinants of the relative subjective price of time and risk aversion System of simultaneous equations

(Dependent variables are subjective interest rates after transformation, equation 1 to 6; equation $\mathrm{n}^{\circ} 7$ is risk aversion; multivariate joint estimation of 6 equations)

We obtain the same mix of explicatives: gender risk, risk aversion and, at a lower level, life expectancy. Risk aversion is positively significant three times out of six. However, risk aversion seems to weight more on the short interest rates. Life expectancy is moderately significant and weights on the long-term part of the term structure. So, the question of the level and slope of the subjective rates appears important. Gender is clearly confirmed as important on the subjective value of time either directly or indirectly through risk aversion. The results are less strong if we consider the role of risk aversion. However, the results of the multivariate SUR method may be hampered by the fact that the dependant variable in the risk aversion equation is not continuous. 


\section{$\underline{\text { Panel analysis }}$}

In order to consider the answers to the question globally, we used a panel analysis by stacking for each individual his 6 observations. The F-test signals a strong individual effect. The means of time relative values are different between individuals.

\begin{tabular}{lll}
\hline & $\begin{array}{l}\text { Pooled B1-B6 ordinal } \\
\text { answers }\end{array}$ & $\begin{array}{l}\text { Pooled subjective interest rates } \\
1 y-50 y\end{array}$ \\
\hline F-stat & 1.76 & 3.50 \\
degrees & 242 & 242 \\
p-value & $0.00^{* * *}$ & $0.00^{* * *}$ \\
\hline
\end{tabular}

Table 16 - Test for the individual effect (1458 pooled observations)

We used a panel test with a random method to take into account the individual average answer. The random method gives an individual a random effect around a mean value. A fixed effect would imply 243 fixed constant coefficients to take into account the individual effect. Dependent variable set is pooled AV1-AV50 which eliminates outliers and yield continuous dependent variable. Explicatives are limited to horizon maturity, gender, risk aversion, life expectancy, planning horizon (S14 variable) and the size of capital (S20 variable). The first explicative variable refers to the time horizon of the relative subjective price of time, i.e. 1, 5, 10, 20, 30 and 50 years. The other explicatives are individual characteristics and are deterministic. A Hausman test to distinguish between a fixed and a random effect was performed. This did not show any difference in the estimated coefficients. The hypothesis of a useful individual fixed is rejected (at the p-value of 0.64). A fixed effect is not necessary per se, and we used a random effect model.

\begin{tabular}{lllll}
\hline & Random effect & & Fixed effect & \\
\hline Explicatives & Coef. & p-value & Coef. & p-value \\
Constant & 0.72 & $0.00^{* * *}$ & & \\
Horizon & -0.02 & $0.00^{* * *}$ & 0.02 & 0.54 \\
maturity & & & & \\
Gender & -0.15 & $0.00^{* * *}$ & -0.10 & $0.06^{*}$ \\
Risk aversion & 0.05 & $0.00^{* * *}$ & 0.05 & $0.00^{* * *}$ \\
Life expectancy & -0.00 & 0.39 & -0.01 & 0.01 \\
Planning & 0.01 & 0.82 & -0.01 & 0.61 \\
horizon & & & & 0.84 \\
Capital & -0.01 & 0.73 & -0.00 & \\
R2 & 0.44 & & 0.45 & \\
Hausman & 0,70 & 0,64 & & \\
\hline
\end{tabular}


Table 17 - Panel estimates of subjective discount rates AV1-AV50 - Random and fixed effects

(Panel estimates with random individual effects, dependant variables are subjective interest rates AV1-AV50 for time horizons from 1 to 50 years using the correspondence table A2 in Annex, $N=243$; independent variables are horizon maturity: 1, 5, 10, 20 30, and 50 years; gender: $\operatorname{man}(0)$ woman(1); risk aversion attitude from 1 to 6 ; life expectancy in number of years as of 2007; planning horizon from 1 to 4, variable S18; capital: size of personal capital from 1(none) to 6(huge), variable S20)

Similar analysis should be performed to set the panel equation explaining risk aversion with gender. The pseudo R2 of the random effect model is considerably lower. This is not confirmed by a significant Hausman test.

\begin{tabular}{lllll}
\hline & Random effect & & Fixed effect & \\
\hline Explicatives & Coef. & p-value & Coef. & p-value \\
Constant & 2.90 & $0.00^{* * *}$ & & \\
Gender & 0.85 & $0.00^{* * *}$ & 0.78 & $0.00^{* * *}$ \\
R2 & 0.02 & & 0.22 & \\
Hausman & 0,89 & 0,35 & & \\
\hline
\end{tabular}

Table 18 - Panel estimates of risk aversion attitude - Random and fixed effects

The two panel regressions explaining the subjective time value and the risk aversion of respondents are estimated jointly. Table 19 presents the results ${ }^{12}$.

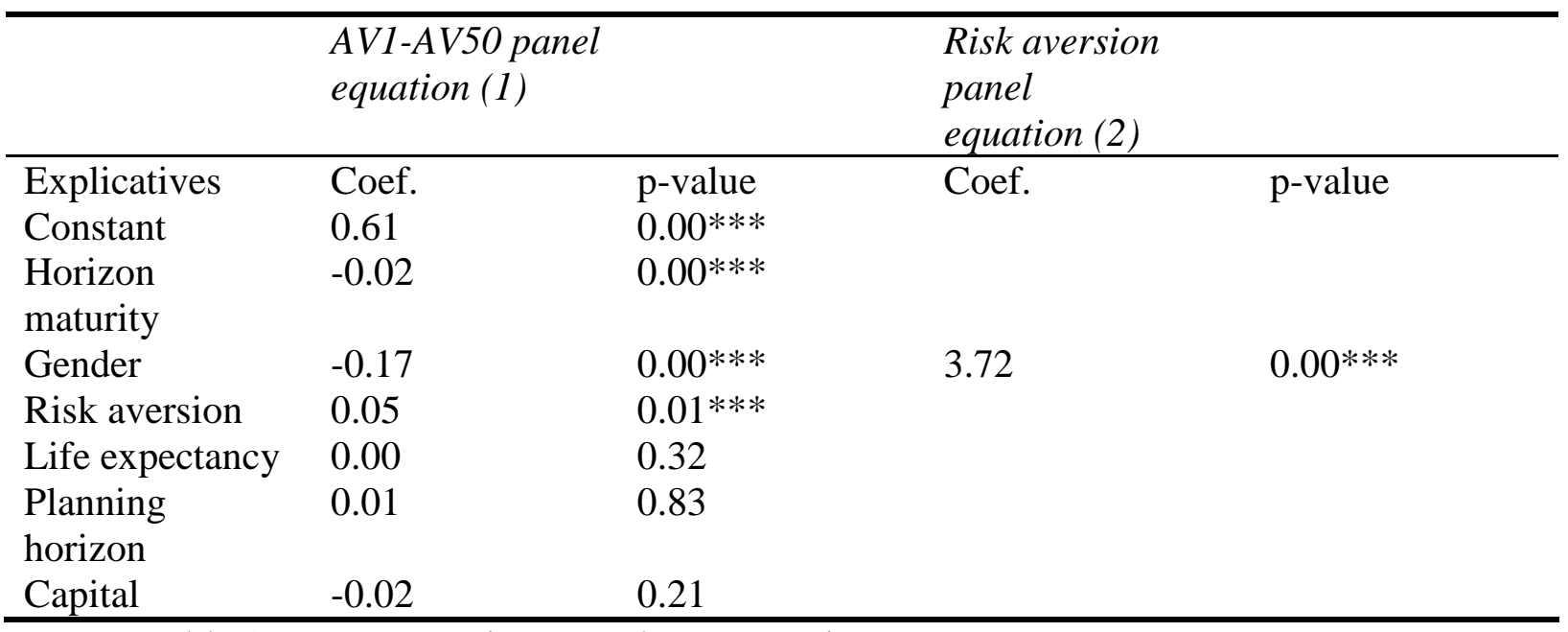

Table 19 - Two equations panel system estimates

(Equation 1 is subjective discount rates fir 1 to 50 years time horizon; equation 2 is risk aversion attitude; eq(1) is estimated with random effects and equation 2 with fixed effects;

\footnotetext{
${ }^{12}$ Similar resulats are obtained if we consider anty fixed or random effect in equation (1) or (2)
} 
dependant variables are subjective interest rates AV1-AV50 for time horizons from 1 to 50 years using the correspondence table A2 in Annex in equation (1) and risk aversion attitude in equation (2); $\mathrm{N}=1458$; independent variables are horizon maturity: 1, 5, 10, 2030 , and 50 years; gender: $\operatorname{man}(0)$ woman(1); risk aversion attitude from 1 to 6 ; life expectancy in number of years as of 2007; planning horizon from 1 to 4, variable S18; capital: size of personal capital from 1(none) to 6(huge), variable S20)

The coefficient of horizon maturity is negative in the AV1-AV50 dependent variables, which is expressed in terms of subjective interest rates. It indicates a term structure of subjective interest rates decreasing with the time horizon. Gender is the first characteristic to influence individual time preference. Women have a lower time preference and a lower subjective value of time. Men are more impatient. Risk aversion is the second psychological attitude that influences time preference. Risk averse people will show at the same time a stronger time preference. They prefer certainty and, all other things being equal, immediacy. On the other hand, risk aversion is per se liked to gender: women are more risk averse than men. This conclusion is important on theoretical grounds because it suggests that the two dimensions of time preference and risk aversion are not isolated. This result is in line with Frederick (2005), who suggests the idea of a common factor behind the time and the risk attitude of individuals. Gender may be that common factor insofar as we saw that it inked with risk aversion.

The simultaneous panel regression system deals with the cross correlation feature of endogenous variables. As a robustness check, we used also a methodology similar to a double least squared estimation. As far as the risk aversion dependant variable in equation (2) is not continuous but ordinal it may yield non normal residuals. We estimated equation (2) using a Poisson regression model. In a first step we estimated equation (2). We checked the normality of residuals and stack them to form a panel vector dragging the individuals risk aversion characteristics orthogonal to gender. In a second step, this residual variable is introduced in equation (1) instead of the risk aversion variable. The panel estimates leads to results similar to those presented table 19 .

$\underline{\text { Limits }}$ 
Our work focuses on pure intertemporal discounting. We do not introduce the hypothesis of hyperbolic discounting. We only deals with the objective measure of the time delay between two times comparisons. A perception bias may exist in absolute term. Contrary to Zauberman et al. (2009) it seems not significant. However this hypothesis is taken into account in a relative way with the delivery of an objective piece of new information on the time delay. It does not measure explicitly the personal perception of time. However, even if the Weber-Fechner law is true, the slope of intertemporal discount rate still remains negative.

\section{Conclusion}

This empirical study confirms the decreasing slope of subjective interest rates. Individuals use a term structure to discount deferred choice preferences. The psychological value of time can be modeled and parameterized using the intercept which is the immediate time preference value and the slope of the decreasing subjective interest rates. An exponential modeling fits the data successfully. A "balanced pressure law" between these two parameters is suggested.

The individual subjective term structure of interest rates seems weakly influenced by social or economic characteristics of the individual. Life expectancy does not seem to influence the level or the shape of the psychological value of time. We found an absence of a tempus fugit effect in the term structure of subjective interest rates. Gender is a variable that strongly influences the level of subjective interest rates. The attitude toward risk also appeared as a determinant of time preference attitude. These two dimensions seem to interact.. This result contradicts the pure intertemporal microeconomic model, which separates the two dimensions. This suggests the need to develop further tests to analyze the disentangling hypothesis.

As further developments we should test the influence of some dependency psychological variables. We referred to smoking, but the literature underlines the role of other addictions like...work for of busy executives. Family status may also be considered as a single may not face the opportunity of one "free hour" in the same way a family with children does. Even if we showed that the downward sloping result is not directly related to the life expectancy, an indirect dependency may exist through choice contexts that are themselves 
linked to the different time episode of human life, i.e. family life, children education, health or desease.

\section{Annex}

\begin{tabular}{|c|c|}
\hline Variables & Answers \\
\hline S2-Gender & $\operatorname{Man}(0)-W o m a n(1)$ \\
\hline S12 - Smoker & Yes(0)-No (1) \\
\hline S14 - Education & 1 to 6 increasing with the level of education \\
\hline S15 - Employed/not & $\begin{array}{l}\text { (1) Employed or would be (i.e. unemployed } \\
\text { students)-not (0) }\end{array}$ \\
\hline S16 - Financial expenses & $\begin{array}{l}\text { From } 1 \text { to } 6 \text { increasing with monthly range of } \\
\text { expenses }\end{array}$ \\
\hline S18 - Financial planning horizon & $\begin{array}{l}\text { From } 1 \text { to } 4 \text { increasing with long term } \\
\text { planning horizon }\end{array}$ \\
\hline S19 - Passing on something to heirs & $\operatorname{yes}(0) / \operatorname{no}(1)$ \\
\hline S20 - Size of personal capital & From 1 to 6 increasing with size \\
\hline S23 - Risk attitude & From 1 (risk lover) to 6 (risk averter) \\
\hline French native language & (1) Yes (0) No \\
\hline $\begin{array}{l}\text { Father's (yes if French) native } \\
\text { language }\end{array}$ & (1) Yes (0) No \\
\hline $\begin{array}{l}\text { Mother's (yes if French) native } \\
\text { language }\end{array}$ & (1) Yes (0) No \\
\hline Birthplace & (1) France (0) others \\
\hline Father's birthplace & (1) France (0) others \\
\hline Mother's birthplace & (1) France (0) others \\
\hline Life expectancy & $\begin{array}{l}\text { In years calculated according to the INED } \\
\text { (French National Institute of Demographic } \\
\text { Studies) } 2007 \text { table of mortality. }\end{array}$ \\
\hline
\end{tabular}

Table A1 - Respondents' characteristics

\begin{tabular}{lllllll}
\hline Horizons & $1 y$ & $5 y$ & $10 y$ & $20 y$ & $30 y$ & $50 y$ \\
\hline 1 & $0.1 \%$ & $0.1 \%$ & $0.1 \%$ & $0.1 \%$ & $0.1 \%$ & $0.1 \%$ \\
2 & $50.0 \%$ & $8.4 \%$ & $4.1 \%$ & $2.0 \%$ & $1.4 \%$ & $0.8 \%$ \\
3 & $300.0 \%$ & $32.0 \%$ & $14.9 \%$ & $7.2 \%$ & $4.7 \%$ & $2.8 \%$ \\
4 & $500.0 \%$ & $55.2 \%$ & $24.6 \%$ & $11.6 \%$ & $7.6 \%$ & $4.5 \%$ \\
5 & $500.0 \%$ & $76.2 \%$ & $32.8 \%$ & $15.2 \%$ & $9.9 \%$ & $5.8 \%$ \\
6 & $500.0 \%$ & $96.1 \%$ & $40.0 \%$ & $18.3 \%$ & $11.9 \%$ & $7.0 \%$ \\
7 & $500.0 \%$ & $113.2 \%$ & $46.0 \%$ & $20.8 \%$ & $13.4 \%$ & $7.9 \%$ \\
8 & $500.0 \%$ & $130.5 \%$ & $51.8 \%$ & $23.2 \%$ & $14.9 \%$ & $8.7 \%$ \\
9 & $500.0 \%$ & $139.0 \%$ & $54.6 \%$ & $24.3 \%$ & $15.6 \%$ & $9.1 \%$ \\
\hline
\end{tabular}

Table A2 - Correspondence between the ordinal answers to questions B1-B6 and C6-C11 and implicit subjective interest rates 
(Choice 1 leads to a negative time preference i.e. a negative subjective interest rates, so they were set close to a null interest rate; for the one year horizon; choices above 3 have been capped; interpolation is carried out looking at the mid-range of the ordinal answer choice1:1h; choice $2: 1,5 \mathrm{~h}$; choice $3: 4 \mathrm{~h}$; choice $4: 9 \mathrm{~h}$; choice $5: 17 \mathrm{~h}$; choice $6: 29 \mathrm{~h}$; choice $7: 44 \mathrm{~h}$; choice 8:65h; choice 9:78h; subjective rates are annual equivalent rates)

\begin{tabular}{llllll}
\hline $\begin{array}{l}\text { Dependent } \\
\text { variable }\end{array}$ & Gender & Risk aversion & Control & LR & $\begin{array}{l}\text { Pseudo } \\
R 2\end{array}$ \\
\hline B1 1y & -0.93 & 0.19 & yes & 42.81 & 0.18 \\
& $0.00^{* *}$ & 1.11 & & $0.00^{* * *}$ & \\
B2 5y & -0.76 & 0.16 & yes & 29.62 & 0.13 \\
& $0.02^{* *}$ & 0.16 & & $0.01^{* *}$ & \\
B3 10y & -0.88 & 0.20 & yes & 42.74 & 0.18 \\
& $0.00^{* *}$ & $0.07^{*}$ & & $0.00^{* * *}$ & \\
B4 20y & -0.89 & 0.15 & yes & 35.76 & 0.15 \\
& $0.00^{* * *}$ & 0.15 & & $0.00^{* * *}$ & \\
B5 30y & -0.81 & 0.15 & yes & 38.35 & 0.17 \\
& $0.01^{* *}$ & 0.15 & & $0.00^{* * *}$ & \\
B6 50y & -0.58 & 0.19 & & 31.60 & 0.14 \\
& $0.04^{* *}$ & $0.07^{*}$ & & $0.00^{* * *}$ & \\
\hline
\end{tabular}

Table A3 - Determinants of the relative subjective price of timeB1-B6

(Individual ordered logit regressions, Gender, risk aversion and other 13 dependant control variables; dependent variables are ordinal answers from 1 to 9 to B1-B6 questions, explicative variables are S2 gender, $\operatorname{man}(0)$ woman(1); S23 risk aversion attitude from 1 to 6; life expectancy in number of years as of 2007; S12: smoker(0) non smoker(1); S14: education from 1 self-taught to 6 master's degree; S16: income level; S18: planning horizon from 1 to 4; S19: passing something on to children; S20: size of personal capital from 1(none) to 6(huge); native language French(1) no(0); father's native language French(1) no(0); mother's language: French(1) no(0); birthplace: France(1) no (0); father's birthplace: France(1) no(0); mother's birthplace: France(1) no(0))

\section{References}

AINSLIE G. [1992]: Picoeconomics, Cambridge University Press

Ainslie G., HASlAm N. [1992], "Hyperbolic Discounting." In George Loewenstein and John Elster (eds.), Choice over time, New York: Russell Sage Foundation, pp. 57-92

BAKER F., JOHNSON M.W., BICKEL W.K. [2003]: "Delay discounting in current and neverbefore cigarette smokers: Similarities and differences across commodity, sign and magnitude", Journal of Abnormal Psychology, vol.1112, pp.382-392.

BJork J.M., Hommer D.W., Grant S.J., Danube C. [2004]: "Impulsivity in abstinent alcohol-dependent patients: relation to control subjects and type 1-/type 2- liketraits", Alcohol, vol.34, pp.133-150.

BREEDEN D. [1986]: "Consumption, production, inflation and interest rates", Journal of Financial Economics, vol.16, pp.3-39. 
BRETTEVILLE-JENSEN A.L. [1999]: “Addiction and discounting”, Journal of Health Economics, vol.18, pp.393-407.

CAIRnS J., VAN DER POOL M. [2000]: "Valuing future private and social benefits: the discounted utility model versus hyperbolic discounting", Journal of Economic Psychology, vol.21, pp.191-205.

CAIRnS J., VAN DER POOL M. [2002]: “A comparison of the discounted utility model and hyperbolic discounting models in the case of social and private intertemporal preferences for health", Journal of Economic Behavior and Organization, vol.49, pp.79-96.

ChUng S., HERRNSTEIN J. [1961]: "Relative and absolute strengths of response as a function of frequency of reinforcement", Journal of Experimental analysis of animal behaviour, vol.4, pp.267-272.

EPSTEIN L., ZIN S. [1989]: "Substitution, risk aversion and the temporal behavior of consumption and asset returns: A theoretical framework", Econometrica, vol.57(4), pp.937969.

EPSTEIN L., ZIN S. [1991]: "Substitution, risk aversion and the temporal behavior of consumption and asset returns: An empirical analysis", Journal of Political Economy, vol.99(2), pp.263-288.

FEATHER P., SHAW W. [1999]: Estimating the cost of leisure for recreation demand models, Journal of Environmental Economics and Management, vol.38, pp.49-65.

FISHER I., [1930]: The theory of interest, New York, MacMillan

FREDERICK S. [2005]: "Cognitive Reflection and Decision Making”, Journal of Economic Perspectives, Volume 19, Number 4, Fall 2005, pp.24-42.

FREDERICK S. [2006]: "Valuing future life and futures lives: A framework for understanding discounting", Journal of Economic Psychology, vol.27, pp.667-680.

Frederick S., Loewenstein G., O’Donoghue T. [2002]: “Time discounting and time preference: A critical review", Journal of Economic Literature, vol. 40(1), pp.351-401.

GreEn L., Fry A.F., Myerson J. [1994]: "Discounting of delayed rewards: A life-span comparison", Psychological Science, vol.5, pp.33-37.

HANSEN L., SingletON K. [1983]: "Stochastic consumption, risk aversion and the temporal behaviour of asset returns", Journal of Political Economy, vol.91, pp.249-268.

Jolibert A., Jourdan P. [2006]: Méthodes de recherche et d'études en marketing, Paris, Dunod Ed.

KAHNEMAN D. [1994]: "New challenges to the rationality assumption" Journal of Institutional and Theoretical Economics, vol.150, pp.18-36

KAhneman D., TVERsKy A. [1979]: "Prospect Theory: An Analysis of Decision under Risk", Econometrica, vol.XVLII, pp.263-291.

KAHNEMAN D., RIIS J. [2005] : Living, and thinking about it: Two perspectives on life. In F.A. HuPPERT, N. Baylis, B. Keverne (Eds.), The science of well-being (pp.285-304). Oxford: Oxford University Press.

KAHNEMAN D., WAKKER P., SARIN R. [1997]: "Back to Bentham? Exploration of experienced utility", Quarterly Journal of Economics, vol. 112, pp.375-405

KIRBY K.N., PETRY N.M. [2004]: "Heroin and cocaine abusers have higher discount rates for delayed rewards than alcoholics or non-drug-using controls", Addiction, vol.99, pp.461-471.

KurZ, M., Spiegelman R., West R. [1973] : "The Experimental Horizon and the Rate of Time Preference for the Seattle and Denver Income Maintenance Experiments" Occasional paper. Stanford, Calif.: Stanford Res. Inst., November 1973.

LAIBSON D. [1996]: "Hyperbolic discount functions, undersaving and saving policy", WP n5635, NBER

LAWRANCE E. [1991] : «Poverty and the rate of time preference : Evidence from a panel data », Journal of Political Economy, Vol. 99, No. 1, pp. 54-77 
LEW D., LARSON D. [2005] Valuing recreation and amenities at San Diego County beaches, Coastal Management, vol.33, pp.71-86

Loewenstein G., PRelec D. [1992]: “Anomalies in intertemporal choice: Evidence and an interpretation", Quarterly Journal of Economics, vol.57, pp.573-598.

OHMURA Y., TAKAHASHI T., KITAMURA N. [2005]: "Discounting delayed and probabilistic monetary gains and losses by smokers of cigarettes", Psychopharmacology, vol.182, pp.508515.

PETRY N. [2001] "Delay discounting of money and alcohol in actively using alcoholics, current abstinent alcoholics, and controls", Psychopharmacology, vol.154, pp243-250

SAMUELSON P.A. [1937]: "A note on measurement utility", Review of Economic Studies, vol.4, pp.155-161.

ROHDE K. [2010], The hyperbolic factor: A measure of time inconsistency, Journal of Risk and Uncertainty, vol.41, pp.125-140

Soman D., Ainslie G.,Li Xiuping, Lynch J., Mitchell A., Read D., Sawyer A., Trope Y., Wertenbroch K., Zauberman G., [2005], "The Psychology of Intertemporal Discounting: Why are Distant Events Valued Differently from Proximal Ones? ", Marketing Letters, 16, 3/4, pp.347-360

SHAPIRO J. [2005]: "Is there a daily discount rate? Evidence from the food stamp nutrition cycle", Journal of Public Economics, vol. 89, pp.303-325.

STROTZ R. [1956]: "Myopia and inconsistency in dynamic utility maximisation", Review of Economic Studies, vol.23, pp.165-180.

THALER R. [1981]: "Some empirical evidence on dynamic inconsistency", Economic Letters, vol.8, pp.201-207.

THALER R., SHEFRIN H. [1981] "An economic theory of self-control” Journal of political Economy, vol. 89 n 2 , pp.392-406

TVERSKY A., KAHNEMAN D. [1992]: "Advances in prospect theory: Cumulative representation of uncertainty", Journal of Risk and Uncertainty, vol.5, pp.297-323.

VON Mises L. [1949]: Human Action, a Treatise on Economics, New Haven: Yale University Press.

WARNER J., PleETER S. [2001] "The personal discount rate: Evidence from military downsizing programs, American Economic Review, vol.91, pp.33-53

WEIL P. [1989] "The equity premium puzzle and the risk-free rate puzzle", Journal of Monetary Economics, vol.24, pp401-421

Zauberman G., Kim K., Malkoc S., BetTman J., [2009], "Discounting Time and Time Discounting:Subjective Time Perception and Intertemporal Preferences", Journal of Marketing Research, Vol. XLVI, pp. 543-556 